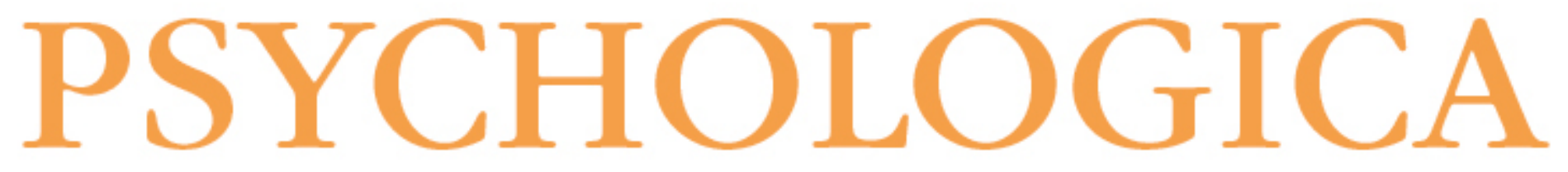

\title{
Reabilitação psicossocial de pessoas com esquizofrenia: estudo de caso
}

Autor(es): $\quad$ Teixeira, Carina; Santos, Eduardo; Abreu, Manuel Viegas; Gonçalves, Patrícia

Publicado por: Imprensa da Universidade de Coimbra

URL

persistente: URI:http://hdl.handle.net/10316.2/5421

DOI: $\quad$ DOI:http://dx.doi.org/10.14195/1647-8606_50_6

Accessed : $\quad$ 26-Apr-2023 14:54:04

A navegação consulta e descarregamento dos títulos inseridos nas Bibliotecas Digitais UC Digitalis, UC Pombalina e UC Impactum, pressupõem a aceitação plena e sem reservas dos Termos e Condições de Uso destas Bibliotecas Digitais, disponíveis em https://digitalis.uc.pt/pt-pt/termos.

Conforme exposto nos referidos Termos e Condições de Uso, o descarregamento de títulos de acesso restrito requer uma licença válida de autorização devendo o utilizador aceder ao(s) documento(s) a partir de um endereço de IP da instituição detentora da supramencionada licença.

Ao utilizador é apenas permitido o descarregamento para uso pessoal, pelo que o emprego do(s) título(s) descarregado(s) para outro fim, designadamente comercial, carece de autorização do respetivo autor ou editor da obra.

Na medida em que todas as obras da UC Digitalis se encontram protegidas pelo Código do Direito de Autor e Direitos Conexos e demais legislação aplicável, toda a cópia, parcial ou total, deste documento, nos casos em que é legalmente admitida, deverá conter ou fazer-se acompanhar por este aviso. 


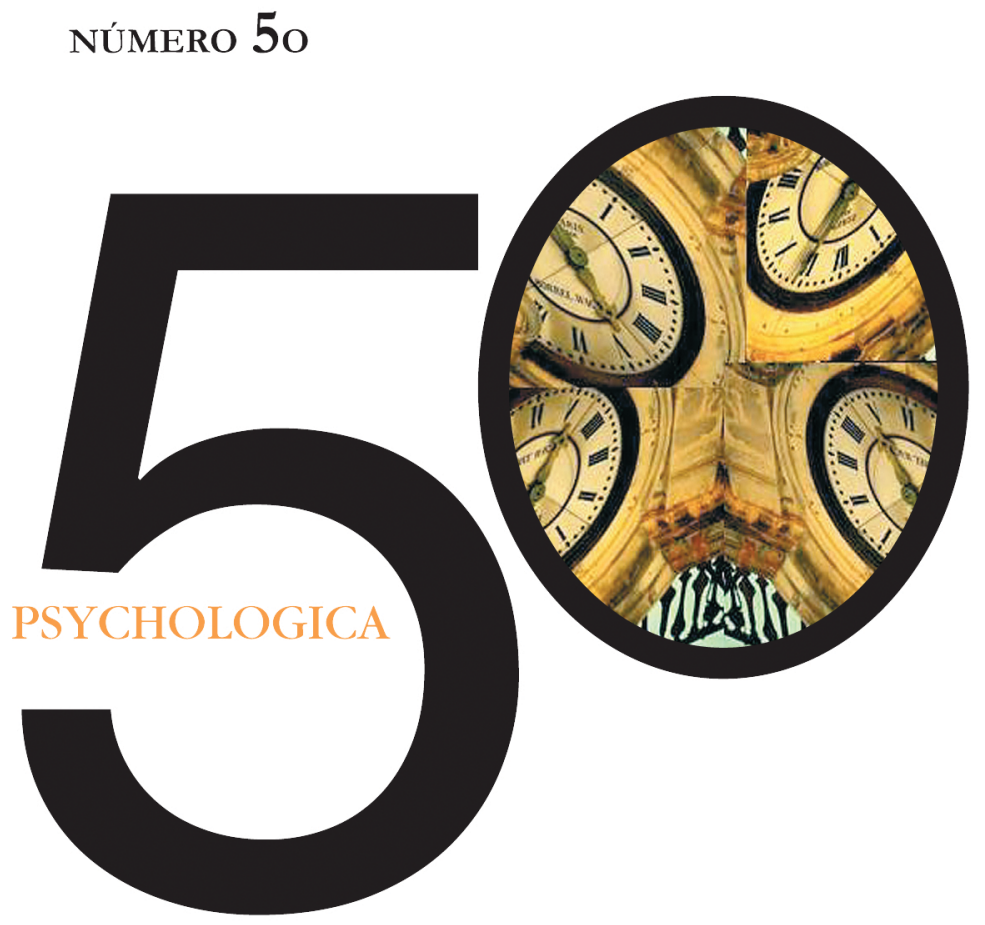

IMPRENSA DA UNIVERSIDADE DE COIMBRA

FACULDADE DE PSICOLOGIA E DE CIÊNCIAS DA EDUCAÇÃO DA UNIVERSIDADE DE COIMBRA 


\title{
Reabilitação Psicossocial de Pessoas com Esquizofrenia: Estudo de Caso
}

\author{
Carina Teixeira', Eduardo Santos ${ }^{2}$, Manuel Viegas Abreu³ Patrícia Gonçalves $^{4}$
}

\begin{abstract}
A mudança de paradigma na área da psiquiatria que tem vindo a ocorrer nos últimos anos com o processo de desinstitucionalização pressupõe o desenvolvimento de respostas de integração comunitária. Estudos realizados noutros países demonstram melhores resultados para programas de reabilitação psicossocial do que internamento em hospital psiquiátrico, embora, em Portugal, os serviços não se coadunem com o estado da arte nesta matéria. Neste sentido, este trabalho tem como principal objectivo conhecer e analisar uma experiência, que pelas suas características é única, de reabilitação psicossocial, na área da doença mental, da região centro do país. Esta investigação constitui um estudo de caso, em que a unidade de análise é uma Instituição Particular de Solidariedade Social, a Associação de Reabilitação Social e Desinstitucionalização de Doentes Psiquiátricos (ARSDOP), na qual se pretendeu conhecer o seu modelo de funcionamento global e, mais especificamente, os modelos de reabilitação profissional e residencial nela desenvolvidos.
\end{abstract}

PALAVRAS-CHAVE: Reabilitação, Esquizofrenia, Emprego.

\section{Introdução}

A mudança de paradigma na área da psiquiatria e saúde mental que tem vindo a ocorrer nos últimos anos com o processo de desinstitucionalização de doentes mentais do foro das psicoses, aliado ao encerramento dos hospitais psiquiátricos, pressupõe o desenvolvimento de condições e respostas que garantam a sua integração efectiva na comunidade.

\footnotetext{
1 Estudante de Doutoramento - Faculdade de Psicologia e de Ciências da Educação da Universidade de Coimbra. Investigadora do Instituto de Psicologia Cognitiva, Desenvolvimento Vocacional e Social da Universidade de Coimbra (IPCDVS - UC).

2 Professor Associado - Faculdade de Psicologia e de Ciências da Educação da Universidade de Coimbra. Coordenador Científico do Instituto de Psicologia Cognitiva, Desenvolvimento Vocacional e Social da Universidade de Coimbra (IPCDVS - UC).

3 Professor Jubilado - Faculdade de Psicologia e de Ciências da Educação da Universidade de Coimbra. Investigador do Instituto de Psicologia Cognitiva, Desenvolvimento Vocacional e Social da Universidade de Coimbra (IPCDVS - UC).

4 Psicóloga da Associação de Reabilitação Social e Desinstitucionalização de Doentes Psiquiátricos (ARSDOP)
} 
No entanto, a criação de estruturas para a integração comunitária de pessoas com doença mental grave tem sido um processo difícil em Portugal. Como salienta Caldas de Almeida (2008), quando se compara, a situação dos nossos serviços, muito centrados no internamento e numa consulta externa, com a situação dos serviços de outros países, que integram acompanhamento clínico, apoio residencial e vocacional, verificamos que estamos ainda muito longe de um modelo ideal de recuperação. Os mitos que envolvem a pessoa com doença mental, nomeadamente acerca da sua perigosidade e pouca capacidade de trabalho, juntamente com a ausência de informação consistente e com base científica demonstrando a efectividade dos serviços de reabilitação psicossocial de base comunitária, têm constituído entraves à mudança de paradigma no nosso país.

Posto isto, no presente trabalho, começamos por apresentar a bibliografia mais significativa relativa à problemática em estudo. Numa primeira fase, é analisado o percurso histórico das formas de tratamento em saúde mental, de forma a melhor compreendermos o contexto da emergência dos novos modelos de reabilitação de base comunitária. De seguida, são abordados alguns aspectos que, actualmente, ainda dificultam e impedem a integração plena da pessoa com doença mental na comunidade. E, por fim, são descritos os modelos de reabilitação psicossocial, nas vertentes profissional e residencial, enfatizando a sua importância para o processo de recuperação dos doentes mentais de evolução prolongada.

De acordo com a revisão da literatura efectuada, e devido à quase inexistência de estudos nacionais nesta área, assumimos a importância de conhecer e analisar experiências de reabilitação psicossocial de doentes do foro das psicoses, mais especificamente portadores de esquizofrenia. Optou-se por realizar um estudo de caso acerca de uma Instituição Particular de Solidariedade Social, a Associação de Reabilitação Social e Desinstitucionalização de Doentes Psiquiátricos (ARSDOP), a qual deposita todos os seus esforços na reabilitação psicossocial da mencionada população. Neste sentido, é feita uma apresentação detalhada da Associação e seus programas. Por fim, é a presentada uma reflexão sobre a informação colhida na ARSDOP, confrontando-a com os modelos teóricos e investigações contemplados na revisão da literatura.

\section{Enquadramento Conceptual}

\section{A doença mental ao longo dos tempos: Da condenação e exclusão ao tratamento e inclusão social}

A compreensão da doença mental está profundamente ligada a determinantes culturais, sociais e históricos. 
Na Antiguidade, a doença mental revestia-se de carácter místico e era interpretada como consequência de possessões demoníacas. Contudo, foi na Grécia Antiga que, pela primeira vez, surgiu uma concepção naturalista da doença mental, com a luta de Hipócrates (460-367 a.C.) para erradicar a explicação demonológica das doenças.

Porém, nos séculos seguintes a concepção da doença mental deixou-se contaminar novamente por conceitos teológicos. Na Idade Média, com raras excepções, as doenças mentais eram predominantemente explicadas por factores sobrenaturais e utilizavam-se terapêuticas penosas, como exorcismos para livrar o corpo dos espíritos malignos. Outra estratégia que esta sociedade adoptou para excluir os considerados insanos foi a "nau dos loucos", que partia cheia e aportava vazia. Durante a Idade Média, e desde muito antes, existiam poucos recursos institucionais destinados aos doentes mentais

Com o lluminismo, no século XVIII, iniciou-se a era da "institucionalização" ou do "grande encarceramento" (Foucault, 1991, referido por Wolff, 2000). Com efeito, a prática da hospitalidade humanista iniciada por S. João de Deus (1495-1550) no hospital que fundou em Granada em pleno Renascimento (1539) só a pouco e pouco se foi difundindo por Espanha, Itália e França. Segundo J-M. Masson (1999), os ideais de humanismo fraterno que caracterizavam essa prática influenciaram Philippe Pinel e eram consonantes com as ideias humanistas da Revolução Francesa, combatendo a degradante concepção das doenças mentais. Impressionado pelas condições desumanas em que viviam os doentes mentais, Pinel conseguiu em 1798 autorização para libertar os asilados, muitos deles algemados há mais de 30 anos.

Os desenvolvimentos do século XIX incluíram a construção de asilos, caracterizados de variadas formas: "locais seguros", "formas de encarceramento" ou "lugares melhores" (Carrier \& Kendall, 2000). Entre 1850 e 1950, os hospitais psiquiátricos aumentaram significativamente, tanto em número, como em dimensões (Leff, 2000), constituindo esta época o século dos asilos.

Em 1930, a introdução do electrochoque vem revolucionar a vida dos hospitais psiquiátricos. É a primeira forma de intervenção possivel para controlar algumas doenças psiquiátricas, como as psicoses. Este método parecia seguro, sem grandes efeitos secundários, se aplicado correctamente, mostrando-se a única alternativa, numa época em que não havia psicofármacos.

Na segunda metade do século XX, a psiquiatria lucrou com os avanços da Bioquímica: descobriram-se os neurotransmissores e, em 1954, o primeiro fármaco com acção sobre psicoses (a clorpromazina) tornou possível diminuir a agitação psicótica.

A introdução e rápida disseminação da medicação antipsicótica levam a que, a partir dos anos 60 do século XX, se inicie um movimento anti-psiquiátrico e 
uma ideologia de tratamento na comunidade, que resultou na implementação da política de desinstitucionalização5. Os profissionais de saúde mental redefiniram o tratamento como um processo no qual os pacientes seriam realojados na comunidade, gerando, deste modo, um novo paradigma: a reabilitação através da inclusão social.

O movimento para a saúde mental na comunidade arrancou numa época de consciência e reformas sociais. Nesse período, assumia-se largamente que os cuidados na comunidade para os doentes mentais seriam mais humanos e terapeuticamente mais eficazes do que os dispensados nos hospitais. Este movimento reflectiu uma justificável preocupação com o bem-estar dos doentes mentais, muitos dos quais tinham uma existência miserável no seio dos hospitais psiquiátricos (Bachrach, 2000).

No entanto, a colocação dos pacientes institucionalizados na comunidade não garante a sua inclusão social. O início do processo de desinstitucionalização trouxe a consciência de que os pacientes crónicos precisariam de preparação para a vida no mundo fora do hospital e como resposta a esta necessidade foram criados programas de reabilitação socioprofissional (Leff \& Warner, 2006).

As perturbações psicóticas, que no passado condenavam muitos doentes a longos períodos no hospital e a altos níveis de incapacidade, passaram, na maioria dos casos, a poder ser tratadas na comunidade, desde que os serviços assegurem intervenções psicossociais em combinação com o tratamento farmacológico.

A OMS, no seu relatório anual de 2001 , define reabilitação psicossocial como "um processo que oferece aos indivíduos que estão debilitados, incapacitados ou deficientes, devido a perturbação mental, a oportunidade de atingir o seu nível potencial de funcionamento independente na comunidade, o que envolve tanto o incremento das competências pessoais como a introdução de mudanças ambientais" (p. 62). Os objectivos são a emancipação do utente, a redução da discriminação e do estigma, a melhoria das competências sociais e pessoais e a criação de um sistema de suporte de longa duração. O direito à habitação, a reabilitação vocacional, a oportunidade de emprego e o acesso a redes de apoio social são aspectos importantes da reabilitação psicossocial.

Por conseguinte, segundo o Relatório da Comissão Nacional para Reestruturação dos Serviços de Saúde Mental em Portugal (2007), "o objectivo da nova política 
de saúde mental é ajudar a pessoa a recuperar plenamente a sua vida na comunidade, com apoio especializado quando necessário, garantir o acesso aos cuidados de saúde mental a todas as pessoas que deles necessitem, fora das grandes instituições e na proximidade dos locais onde as pessoas vivem e promover a reabilitação e a integração na sociedade, em articulação com outros serviços da comunidade" (p.81).

O tratamento e a reabilitação, nesta perspectiva holística, são interdependentes. O tratamento pretende limitar a sintomatologia, diminuir pensamentos bizarros e sentimentos de ansiedade e normalizar o comportamento. A reabilitação pretende capacitar a pessoa disfuncional para atingir o nível máximo de funcionamento pessoal, social, profissional e familiar, no meio menos restritivo possível (Comissão Nacional para a Reestruturação dos Serviços de Saúde Mental, 2007).

A partir dos anos 90 desenvolveu-se uma nova visão da reabilitação que atribui uma grande importância à experiência das próprias pessoas com doença mental, às suas necessidades e aspirações, e ao seu percurso pessoal para a recuperação (recovery). Allot e colaboradores (2002, referido por Crowe, Deane, Oades, Caputi \& Morland, 2006) sugeriram que os indivíduos deveriam ser apoiados no seu próprio desenvolvimento pessoal, enfatizando a construção da auto-estima e da identidade, bem como a procura de um papel significativo na sociedade. Neste sentido, recovery não significa necessariamente restauro do pleno funcionamento ou regresso ao estado pré-morbido (Buckley, Bahmiller, Kenna, Shevitz, Powel, \& Fricks, 2007); significa, porém, construção de forças e recursos pessoais, que permitem desenvolver mecanismos de coping e capacitam os indivíduos a serem participantes activos dos seus cuidados de saúde (Crowe et al., 2006).

Anthony (1993) definiu recovery como um processo único, profundamente pessoal, de mudança de atitudes, valores, sentimentos, objectivos, competências e papéis, envolvendo o desenvolvimento de novos significados e objectivos de vida, enquanto um processo de crescimento que vai além dos efeitos catastróficos da doença mental.

Estas perspectivas implicam que o conceito de recovery não se deverá restringir às definições do modelo médico (alívio dos sintomas) ou às definições do modelo clássico de reabilitação (melhorar o funcionamento), mas deverá expandir para enfatizar os processos psicológicos de recuperação. Em suma, os serviços de saúde mental devem criar condições que favoreçam a auto-determinação e a procura de um caminho pessoal, individualizado, das pessoas com problemas de saúde mental. 


\section{Barreiras à integração das pessoas com doença mental severa}

A desinstitucionalização não tem sido um sucesso inqualificável e os cuidados na comunidade ainda se deparam com muitos problemas operacionais. Entre as razões para a falta de melhores resultados está o facto dos governos não transferirem as fontes dos hospitais psiquiátricos fechados para os cuidados na comunidade; os profissionais não terem sido adequadamente preparados para aceitarem a mudança de papéis e por o estigma vinculado às perturbações mentais permanecer forte (WHO, 2001).

A literatura sugere que as barreiras à integração socioprofissional das pessoas com doença mental severa, nomeadamente, esquizofrenia, incluem, entre outras, os efeitos da própria doença, o estigma e discriminação, a falta de serviços clínicos e vocacionais apropriados, os desincentivos ao trabalho causados por políticas estatais, o nível de pobreza e as elevadas taxas de desemprego gerais.

Os efeitos da doença psicótica constituem barreiras à integração, na medida em que os sintomas positivos (alucinações, delírios) podem dominar a vida dos pacientes e interferir com a sua capacidade para interagir com os outros, executar tarefas e pensar claramente. Por sua vez, os sintomas negativos (apatia, pouca motivação, perda geral do interesse pela vida) tornam muito difícil para o paciente procurar trabalho, ir a uma entrevista, cumprir as exigências de um emprego ou formar relações com os colegas (Leff \& Warner, 2006).

As atitudes da sociedade em geral contribuem, também, para a dificuldade que as pessoas com esquizofrenia encontram na integração social e entrada no mercado de trabalho. Esta situação deve-se, por um lado, ao estabelecimento de uma ligação com comportamentos violentos (ligação que é exagerada pelos media) e, por outro lado, à dificuldade em partilhar e perceber as experiências induzidas pela esquizofrenia. As pessoas desejam distanciar-se daqueles que têm doença mental, como é mostrado pela sua relutância em trabalhar com eles, casar com eles, viver próximo deles e tê-los como amigos (Leff e Warner, 2006).

Os mitos sobre a doença mental e a estigmatização do doente continuam a existir, mesmo entre profissionais da área da saúde. Além do sofrimento devido à sua doença, as pessoas com doença mental vêem-se ainda confrontadas com a discriminação da sociedade, com a negação de direitos e liberdades básicas, bem como com restrições no acesso a cuidados de saúde, protecção social e oportunidades de emprego (Comissão Nacional para Reestruturação dos Serviços de Saúde Mental, 2007).

Neste sentido, Cook (2006) refere que entre uma amostra aleatória de pessoas com esquizofrenia nos Estados Unidos, apenas $23 \%$ dos pacientes em ambulatório recebiam serviços de reabilitação vocacional. O mesmo acontece nos serviços 
clínicos, sendo que uma grande proporção de pessoas com doença mental não tem acesso a tratamento ou o mesmo não é adequado.

Por outro lado, quando são empregados, os doentes vão perdendo os seus benefícios, sendo que há evidência de que os programas de benefícios da Segurança Social desencorajam aqueles que são capazes de trabalhar, apresentando-se, desta forma, como barreiras ao emprego. O efeito do desincentivo ao trabalho é evidente em estudos que comparam os resultados de emprego de indivíduos que recebem com os que não recebem apoio público por incapacidade: aqueles que recebem benefícios por incapacidade têm significativamente menos probabilidade de trabalhar competitivamente, trabalhar 40 ou mais horas por mês e ter rendimentos elevados, independentemente da condição de estudo, características clínicas e demográficas e experiência de trabalho (Cook, 2006).

Outro aspecto significativo diz respeito ao nível de pobreza, pelo que, mesmo as pessoas com doença mental que possuem benefícios por incapacidade são levadas, frequentemente, a um "poverty trap" (armadilha da pobreza). Muitas vezes, o nível de pobreza previne os indivíduos com competências de trabalho adequadas de uma procura bem sucedida, pois, quando residem em zonas onde o trabalho é escasso, não têm acesso a transporte para sair das suas comunidades e procurar trabalho. A pobreza desqualifica os indivíduos de obter trabalhos para os quais necessitam de ter as suas próprias ferramentas, uniformes ou outros equipamentos. A pobreza inibe aqueles com baixo nível educacional de obter formação para melhorar os níveis de aptidão. A investigação confirma que a pobreza é um importante mediador da relação entre doença mental e desemprego, em alguns casos com maior influência na participação no mercado de trabalho do que a perturbação psiquiátrica em si mesma (Cook, 2006).

Outra barreira à integração profissional de pessoas com problemas de saúde mental diz respeito às elevadas taxas de desemprego gerais actuais. Elevadas taxas de desemprego geralmente significam que os empregadores podem escolher entre um grande número de candidatos. Mesmo quando a política das organizações é "igualdade de oportunidades", os candidatos com incapacidades estão em desvantagem no processo de selecção. Deste modo, é necessário ser realista sobre as perspectivas de emprego dos doentes mentais crónicos, neste contexto actual de desemprego prevalecente em muitos países ocidentais. As perspectivas de trabalho em regime aberto para os pacientes podem ser fracas, em função da dificuldade de justificar as prolongadas interrupções da prestação de trabalho e das elevadas exigências em termos de competitividade (Leff \& Trieman, 2000). 


\section{Modalidades de Reabilitação Psicossocial}

Os modelos de reabilitação psicossocial, desenhados para assegurar cuidados integrados na comunidade, foram desenvolvidos e avaliados em muitos países. O Relatório da Comissão Nacional para a Reestruturação dos Serviços de Saúde Mental (2007) indica que os estudos que comparam os serviços de reabilitação psicossocial com os tradicionais serviços de base hospitalar demonstram que os primeiros são mais efectivos e largamente preferidos pelos pacientes e suas famílias.

A reabilitação psicossocial inclui diversas valências, entre as quais, a reabilitação profissional (formação profissional, emprego apoiado, emprego protegido) e a reabilitação residencial (actividades de vida diária, relações de grupo, gestão do dinheiro e do orçamento doméstico), as quais serão descritas de seguida.

\subsection{Reabilitação Profissional: o espectro dos programas de trabalho}

O emprego é um passo fundamental para a recuperação. Ter um emprego proporciona uma estrutura ao dia-a-dia, objectivos com significado, auto-estima, rendimentos, alargamento da rede social e outras mudanças que ajudam os pacientes a desenvolver esperança e mudança na auto-imagem (Becker, Drake \& Naughton, 2005).

Dentro do campo da reabilitação psiquiátrica, a maior parte dos pacientes considera o emprego um elemento-chave no processo de recuperação. Do mesmo modo, os membros da família, os profissionais de saúde mental, os políticos e a sociedade em geral vêem o emprego como uma prioridade e um resultado valorizado (Bond, 2004).

Numerosos estudos indicam que os individuos com doença mental querem trabaIhar, se consideram capazes de trabalhar e expressam a necessidade de formação e serviços de apoio (Cook, 2006).

A investigação tem abordado duas questões maiores: São os programas de reabilitação profissional eficazes a empregar pessoas com doença mental? As pessoas com doença mental severa apresentam um melhor curso da doença se estiverem empregadas?

\subsubsection{Formação Profissional}

As pessoas com esquizofrenia desconsideram, muitas vezes, os estudos e, devido à sua condição severa, têm dificuldades no desenvolvimento de competências e conhecimentos essenciais que os qualifiquem para um trabalho. Muitos indivíduos com perturbação mental não possuem a formação necessária para construir uma 
carreira, pois o começo da doença ocorre cedo, muitas vezes interrompendo o ensino secundário e superior.

Os dados mostram que este grupo tem falta de qualificação profissional ou formação, o que, em parte, leva a um mau ajustamento e a uma adaptação pobre quando entram no mercado de trabalho (Iraurgi, Bombin \& Imaz, 1999).

O estudo de Iraurgi et al. (1999) teve como objectivo avaliar o impacto de um programa de formação profissional em pessoas jovens com diagnóstico de psicose como elemento de reabilitação psicossocial. As hipóteses colocadas foram: a formação contribuirá para o alargamento da sua rede social, aumento de competências sociais e melhoria no bem-estar psicológico; a aprendizagem de competências de trabalho e o assumir de responsabilidades terá algum efeito em termos de estabilização psicopatológica? O programa estava dividido em dois módulos. O primeiro, que era, de facto, a base do programa, consistia num curso de restauração de paredes e telhados, com o objectivo de dotar os formandos com as técnicas do trabalho da pintura. O segundo módulo consistia em dois subprogramas de formação: o módulo de competências sociais básicas e o módulo de competências profissionais. Este estudo verificou que, através do curso de formação, a rede social foi aumentada, o que é óbvio se considerarmos que cada participante esteve em contacto com os outros na formação. Além disso, quando o curso terminou foi observado um aumento nas competências sociais dos participantes e um melhor controlo da doença.

A disfunção social é uma característica definidora da esquizofrenia, pelo que o treino de competências sociais é um componente essencial da formação profissional nesta população. Este tipo de formação é caracteristicamente conduzido em pequenos grupos, o que proporciona a cada indivíduo uma oportunidade adequada para ensaiar. Os conteúdos dos programas de formação são organizados em currículos que incluem, por exemplo, o desenvolvimento de competências de entrevista de emprego e de estabelecimento de diálogo. A formação em competências sociais é claramente eficaz em aumentar o uso de comportamentos específicos, como fazer questões e adequar o volume da voz. A duração da formação pode variar entre 4 a 8 sessões para uma competência muito circunscrita, e de 6 meses a 2 anos para um programa de treino de competências abrangente (Bellack, 2004).

Dado o problema invariante de generalização e aplicação no mundo real, a formação deverá focar as competências que são, actualmente, relevantes para vida do indivíduo. 


\subsubsection{Emprego Protegido}

O termo emprego protegido refere-se a situações em que as pessoas com incapacidade são, tal como o nome indica, efectivamente, protegidas do trabalho competitivo e dos requisitos de produtividade do mercado aberto. O emprego protegido (ou "terapia industrial") foi desenvolvido no norte da Europa e nos EUA depois da Segunda Grande Guerra e é considerado por muitos, actualmente, um modelo institucional e segregador (Leff \& Warner, 2006).

Nas oficinas protegidas, uma vasta gama de tarefas semi-especializadas eram desempenhadas, frequentemente por contratos obtidos da indústria privada. A maioria dos empregados das oficinas protegidas eram pagos por peça, o que significa que trabalhadores severamente incapacitados podiam ser contratados, mas se a sua velocidade de trabalho fosse lenta, podiam ganhar abaixo do salário mínimo (Leff e Warner, 2006).

O perfil financeiro da maioria dos projectos de emprego protegido assemelha-se ao de uma pequena empresa. As actividades desenvolvidas têm raramente cariz capital, mas requerem elevado investimento laboral. O défice entre as vendas e os gastos é corrigido por fontes externas, normalmente subsídios ou apoios das autoridades de saúde ou locais (Hallam e Schneider, 1999).

A ideia na qual o emprego protegido é baseado não é, na sua essência, diferente daquela que predominou nas unidades de reabilitação hospitalares, nomeadamente o desempenho de uma série gradual de tarefas que progressivamente dotaria o paciente de competências de trabalho. A diferença é a de que uma grande proporção de pacientes tem a expectativa de fazer a transição para o mercado normal de trabalho (Leff, 2008).

As oficinas de emprego protegido têm perdido a popularidade. É defendido que o trabalho protegido remunerado não leva aos mesmos benefícios não vocacionais - tais como melhor controlo dos sintomas, aumento da auto-estima e melhoria na qualidade de vida - do emprego competitivo (Bond et al., 2001, referido por Leff \& Warner, 2006).

O trabalho traz benefícios quando proporciona um veículo para a expressão de capacidades e criatividade, sendo que a maior parte do trabalho em indústria não está desenhado para corresponder a esta necessidade (Moreton, 1992). No entanto, os defensores do emprego protegido apontam que para algumas pessoas com capacidade de funcionamento limitada, os serviços protegidos podem ser o único trabalho viável. 
Para abordar algumas das preocupações dos críticos, é possível reestruturar as oficinas protegidas, de modo a se assemelharem às empresas sociais ${ }^{6}$ (Leff e Warner, 2006). O envolvimento dos trabalhadores no planeamento dos negócios tem potencial de aumentar os benefícios não vocacionais do trabalho. Um estudo de pacientes em emprego protegido demonstrou que o nível de auto-estima dos trabalhadores estava positivamente relacionado com apenas um factor - o grau de importância que o trabalhador sentia ser atribuído ao seu trabalho (Dick e Shepherd, 1994, referido por Leff \& Warner, 2006). Este resultado sugere que quanto mais o trabalhador se apercebe do valor do produto do negócio para a comunidade, melhor será o seu bem-estar psicológico.

Mas será o emprego protegido um fim em si mesmo? Ou talvez possa ser modificado com o objectivo chave de facilitar a transição com sucesso das pessoas com incapacidade de emprego protegido para mercado aberto. Moreton (1992) sugere que as oficinas protegidas deveriam concentrar-se na formação e desenvolvimento de novas competências, envolvendo soluções tecnológicas contemporâneas, mais do que nos salários, resultados e produtividade.

\subsubsection{Programas de Emprego Apoiado: do Emprego de Transição ao Modelo de Colocação e Apoio Individual}

\section{Emprego de Transição}

Os programas de emprego de transição são os precursores da abordagem do emprego apoiado.

\footnotetext{
6 Uma alternativa à competitividade no mercado de trabalho consiste em criar empresas geridas pelos pacientes, cumprindo, deste modo, uma dupla missão - desenvolver um produto ou serviço necessário e empregar pessoas em situação de desvantagem. As empresas sociais operam em mercado aberto em competição com empresas públicas e privadas.

As empresas sociais foram pioneiras em Itália como resposta ao programa de desinstitucionalização, o qual levou à proibição de quaisquer admissões em hospitais psiquiátricos por toda a Itália (Leff, 2008) A primeira empresa para pacientes psiquiátricos desinstitucionalizados foi criada em Trieste e prestava serviços na área da limpeza e manutenção de edifícios públicos. Em 1994, o consórcio em Trieste expandiu para incluir um hotel, um Café, um restaurante, uma empresa de transportes e uma companhia de restauração de edifícios (Leff, 2008)

$\mathrm{Na}$ Europa, cerca de 10000 indivíduos com doença mental encontram-se a trabalhar em empresas sociais (WHO, 2001). Estas empresas apresentam um certo número de vantagens relativamente aos programas de emprego protegido e apoiado. Cada projecto oferece uma variedade de postos de trabalho com níveis diferentes de responsabilidade e diferentes exigências de capacidade de iniciativa. Trata-se de um benefício para os pacientes de nível educacional mais elevado, capazes de desempenhar uma actividade administrativa, ou pelo menos executar tarefas mais variadas e estimulantes (Leff \& Trieman, 2000). No presente trabalho, optou-se por não descrever com mais pormenor as empresas sociais, pelo facto do caso em análise na segunda parte (Associação de Reabilitação Social e Desinstitucionalização de Doentes Psiquiátricos) não desenvolver este tipo de projecto.
} 
O emprego de transição é parte integral da filosofia do modelo de clube psicossocial originário dos Estados Unidos na década de 70. Os funcionários do clube negoceiam com os potenciais empregadores na base de que a tarefa será realizada, independentemente do absentismo imprevisivel dos pacientes. Esta garantia torna-se efectiva, assegurando-se que se um paciente faltar ao emprego, será substituído por outro, ou mesmo, caso seja necessário, por um dos funcionários do clube (Leff \& Trieman, 2000).

Numa primeira fase, os membros são inseridos em unidades de trabalho durante oito horas por dia com o objectivo de desenvolverem competências de trabalho. Quando um membro é considerado estar preparado para trabalhar em mercado normal, o técnico (Job Coach) encontra um posto numa empresa na área local e aprende como exercer as funções do emprego. Seguidamente, o técnico treina o membro seleccionado nas competências necessárias e coloca-o no posto por um determinado período, geralmente seis meses. Após este tempo, o membro tem de encontrar ou ser colocado num novo posto e a vaga é preenchida por outro membro (Leff, 2008).

O objectivo do emprego de transição é dotar o paciente com as competências básicas de trabalho que o capacitarão a passar para um posto permanente não apoiado em mercado normal de trabalho.

Algumas críticas têm sido feitas a este modelo de emprego. O emprego de transição apenas proporciona oportunidades de trabalho de tempo limitado criadas pelos técnicos de uma agência, não considerando as preferências individuais dos utentes (Becker, Bebout \& Drake, 1998). Outra crítica a este modelo tem a ver com o tempo excessivo que os pacientes passam em unidades de trabalho até fazerem a transição para o mercado normal. Um estudo retrospectivo de um programa de clube psicossocial bem considerado mostrou que a média de tempo gasta no clube (em unidades de trabalho) antes da primeira colocação de um membro em emprego de transição era 356 dias (Henry, Barreira, Banks, Brown \& McKay, 2001, referido por Bond, 2004).

Em suma, a evidência do sucesso deste programa é pouca e a insatisfação com esta abordagem aplicada às pessoas com doença mental severa levou ao desenvolvimento do modelo de emprego apoiado (Leff, 2008).

\section{Emprego Apoiado}

Mais adequado para a pessoa com doença mental, que pode não ser capaz de tolerar o stress da mudança de emprego ou de aprender novas tarefas facilmente é o modelo de emprego apoiado. 
O emprego apoiado foi conceptualizado no início da década de 80 (Wehman \& Moon, 1988, referido por Becker, Drake, Naughton, 2005) como uma abordagem colocação-formação, contrariando a prática da enfatização da avaliação e formação pré-vocacional (i.e., o modelo de formação-colocação).

Este programa difere do modelo de transição no facto do emprego ser permanente. No início da colocação, a pessoa com doença mental é totalmente apoiada por um técnico. À medida que o trabalhador adquire as competências necessárias e ganha confiança na sua capacidade para desempenhar tarefas, o apoio é gradualmente retirado e fornecido a outro paciente. Como resultado, o número de postos de emprego apoiado continua a crescer ao longo do tempo. As competências e preferências dos indivíduos podem ser consolidadas seleccionando um emprego apropriado, e é possível a progressão para postos melhor remunerados (Leff, 2008).

O termo "emprego apoiado" refere-se, por um lado, a um estatuto de emprego e, por outro, a um programa de emprego. Como estatuto de emprego, o termo refere-se a emprego competitivo em serviços de trabalho consistentes com as forças, recursos, prioridades, preocupações, capacidades, interesses, e escolha informada, para indivíduos com as mais significantes incapacidades para quem o emprego competitivo não ocorre tradicionalmente; ou para quem o emprego competitivo tenha sido interrompido como resultado de uma incapacidade significativa. Como prática, o emprego apoiado refere-se a programas com vista a ajudar pessoas com incapacidade a encontrar e manter este tipo de empregos (Rehabilitation Act Amendments, 1998, referido por Bond, 2004).

O emprego apoiado para pessoas com doença mental severa é uma prática baseada na evidência, fundamentada em resultados convergentes de estudos de conversão de tratamento em hospital de dia em emprego apoiado e em ensaios controlados aleatoriamente, comparando emprego apoiado com uma variedade de abordagens alternativas (Bond, 2004). Estas linhas de investigação sugerem que entre $40 \%$ a $60 \%$ dos pacientes envolvidos em emprego apoiado obtêm emprego competitivo. Por outro lado, menos de $20 \%$ de pacientes similares atingem o mercado normal quando não envolvidos em emprego apoiado.

Um bom número de estudos controlados aleatoriamente em diferentes mercados de trabalho e economias, incluindo o Canadá, Europa, Hong Kong e Estados Unidos documentam que o emprego apoiado é mais eficaz do que as abordagens vocacionais tradicionais, as quais requerem a participação em actividades de preparação para o trabalho (Becker, Whitley, Bailey, \& Drake, 2007).

As pessoas em recuperação que mantêm emprego competitivo por períodos contínuos mostram benefícios, tais como auto-estima aumentada e melhor controlo dos sintomas, embora, por si mesmo, o envolvimento em emprego apoiado 
não tenha impacto sistemático em resultados não vocacionais, até mesmo em resultados indesejáveis, como hospitalizações (Bond, 2004).

O procedimento de emprego a poiado na colocação de pessoas com doença mental em mercado competitivo sem um período extenso de formação profissional levantou várias questões. Há preocupação de que este programa produza stress laboral susceptivel de piorar os sintomas psiquiátricos. Beddel, Draving, Parrish, Gervey e Guastadisegni (1998) avaliaram a experiência de pacientes envolvidos em emprego apoiado e num programa tradicional de "formação e colocação"7, de modo a descrever e comparar mudanças na percepção do self, em função das experiências vocacionais; experiências positivas e negativas associadas ao trabaIho; mudanças desejadas no programa actual; escolha do paciente de emprego apoiado ou formação tradicional e quantidade de stress experienciado no trabalho. Os resultados indicaram que ambos os tipos de método tinham efeitos positivos, com poucas diferenças entre eles, sugerindo que o emprego apoiado não tem efeito negativo sobre os pacientes, comparando com um programa que utiliza formação profissional extensa.

No entanto, as trajectórias a longo prazo de participantes em emprego apoiado não têm sido claras. Becker, Whitley, Bailey e Drake (2007) realizaram um estudo exploratório acerca das trajectórias de adultos com incapacidade psiquiátrica que participaram em emprego apoiado. Becker e colaboradores (2007) voltaram a entrevistar 38 de 78 participantes com doença mental severa, oito a doze anos após se terem envolvido em emprego apoiado. No período de follow-up, a grande maioria (82\%) trabalhava em emprego competitivo. Os participantes reportaram numerosos benefícios relacionados com o emprego, incluindo melhorias na auto-estima, relações interpessoais e controlo da doença. A doença psiquiátrica era a maior barreira ao trabalho; o emprego a tempo parcial e o apoio contínuo os maiores facilitadores. Três temas coincidentes emergiram da análise qualitativa como influências percebidas como significativas no comportamento relacionado com o trabalho dos participantes. Em primeiro lugar, o controlo com sucesso dos sintomas e o dispor de estratégias de coping apropriadas parece desempenhar um papel importante na manutenção de um emprego. Em segundo lugar, os participantes geralmente preferiam trabalhar a tempo parcial, devido às menores exigências envolvidas e por permitir a manutenção dos direitos da Segurança Social e dos Cuidados de Saúde. Por último, os participantes manifestaram a importância da colocação individual e serviços de apoio, afirmando que eram condições imperativas para fazer transições de sucesso entre empregos ou do desemprego para o emprego.

7 O programa vocacional de "formação e colocação" avaliado na investigação de Beddel e colaboradores (1998) foi Formação Pré-Vocacional Remunerada (Paid Prevocational Training). 
Em suma, há boa evidência para a efectividade do emprego apoiado nos Estados Unidos, embora haja ainda pouca investigação nos países europeus.

\section{Colocação e Apoio Individual}

O programa de colocação e apoio individual não constitui um modelo isolado, mas sim um aperfeiçoamento do emprego apoiado. A posição de Bond (2004) é a de que este modelo constitui uma estandardização dos princípios do emprego apoiado, de modo que este possa ser claramente descrito, cientificamente estudado e implementado em novas comunidades.

Durante a última década nenhum novo modelo de emprego apoiado para pessoas com doença mental severa, articulando um conjunto de princípios diferentes daqueles do modelo de colocação e apoio individual, apareceu na literatura. Por isso, faz sentido considerar os princípios deste modelo como o ponto de partida para os princípios do emprego a poiado, reconhecendo que acréscimos, aperfeiçoamentos e exclusões são todos processos numa abordagem empírica para definir uma prática baseada na evidência.

A contribuição do modelo de colocação e apoio individual não foi a criação de novas técnicas, mas a destilação do melhor conhecimento no campo e a rejeição de ideias infundadas. Duas assunções em voga foram descartadas, porque a investigação provou que não eram úteis. A primeira refere-se ao facto das pessoas com doença mental severa precisarem de um período longo de preparação vocacional antes de entrarem num emprego competitivo, de modo a tornarem-se "prontas" para o trabalho e identificarem objectivos de carreira. A segunda diz respeito à premissa de que os serviços de reabilitação deveriam ser fornecidos separadamente dos serviços de saúde mental (Bond, 2004).

Bond $(1998 ; 2004)$ sublinhou muitos princípios desta abordagem:

\section{Elegibilidade baseada na escolha da pessoa em reabilitação}

Dentro da literatura geral da esquizofrenia, numerosos estudos têm procurado identificar preditores do funcionamento vocacional. Certamente, muitos critérios usados para excluir as pessoas dos serviços vocacionais são baseados em falsas crenças. O resultado mais crucial é que os estudos de emprego apoiado falharam a encontrar quaisquer factores específicos (tais como, diagnóstico, sintomatologia, idade, género, grau de incapacidade, hospitalizações anteriores, experiência de trabalho, motivação, habilitações literárias, história de abuso de substâncias) que pudessem predizer melhores resultados no emprego. Por outras palavras, a literatura não fornece nenhuma justificação empírica para excluir qualquer consumidor (Bond, 2004; Leff \& Warner, 2006). É uma abordagem baseada na 
escolha da pessoa em reabilitação, sendo que o único requisito para admissão é o desejo de trabalhar num emprego competitivo.

\section{Integração da reabilitação vocacional nos serviços de saúde mental}

A investigação revela que melhores resultados podem ser obtidos se os programas vocacionais forem parte integrada de uma equipa de saúde mental, mais do que serem proporcionados por uma entidade separada.

Drake, Becker, Bond e Mueser (2003) identificaram quatro benefícios de abordagens integradas: 1) maior envolvimento dos consumidores, 2) melhor comunicação entre técnicos de emprego e clínicos, 3) sensibilização dos clínicos para a importância de focar o emprego e 4) incorporação de informação clínica nos planos vocacionais.

\section{Serviços Focados em Emprego Competitivo}

Os técnicos de emprego ajudam as pessoas a encontrar empregos competitivos onde os utentes recebam, pelo menos, o ordenado mínimo e onde estejam integrados em serviços de mercado normal, não passando por experiências de emprego protegido, segregado e pré-vocacional (Becker, Drake \& Naughton, 2005). Neste sentido, os defensores do modelo de colocação e apoio individual afirmam que a maior parte das pessoas com doença mental severa pode conseguir emprego competitivo e que os serviços de emprego protegido são desnecessários, ainda que esta possa ser uma conclusão altamente questionável.

\section{Procura rápida de emprego e colocação}

A investigação sugere que a formação para o emprego não aumenta a probabilidade de eventual emprego competitivo e que a colocação rápida apresenta mais sucesso. Oito em nove estudos controlados demonstraram melhores resultados de trabalho para clientes que embarcaram em procura rápida de emprego e colocação em vez de passarem por avaliação, treino de competências e aconselhamento vocacional (Leff \& Warner, 2006).

Os estudos recentes estão a examinar o treino de competências fornecido ao mesmo tempo do programa de emprego apoiado, mais do que como um passo preparatório. O objectivo destas estratégias é melhorar a performance no emprego. Se estas intervenções são proporcionadas a pós o consumidor obter um emprego, pode não apenas o princípio da procura rápida de emprego ser mantido, mas também a formação ser personalizada à situação de trabalho, que intuitivamente deverá ser uma intervenção mais forte (Bond, 2004).

\section{Atenção às preferências da pessoa com doença mental}

A procura de trabalho num programa de emprego apoiado é idealmente baseada nas preferências dos utentes, potencialidades e experiência de trabalho prévia, e não a partir dos empregos disponíveis e nos julgamentos dos cuidadores (Bond, 2004; Leff \& Warner, 2006). A maior parte das pessoas com doença mental tem 
preferências específicas acerca do tipo de trabalho, horário, localização e remuneração. A utilização destes critérios origina taxas mais elevadas de contratações e uma maior estabilidade no trabalho (Becker, Bebout \& Drake, 1998). Além disso, mudanças nas preferências têm mais probabilidade de ocorrer após os utentes estarem em determinado emprego do que após aconselhamento vocacional, sugerindo que a experiência de trabalho é a melhor abordagem para seleccionar o melhor local (Becker et al., 1998).

\section{Avaliação e Apoio Contínuos}

A avaliação mais válida é feita depois da pessoa com doença mental começar a trabalhar, não antes, como ocorre nos programas de reabilitação vocacional tradicionais (Leff \& Warner, 2006). O apoio é mantido por período indefinido, sendo que os programas de emprego apoiado permanecem ligados ao suporte dos consumidores durante muito tempo após a colocação, evitando os prazos artificiais para o seu término (Bond, 2004). Um estudo de follow-up, conduzido três anos e meio após colocação através de um programa de emprego apoiado, verificou que o emprego era quase três vezes mais provável para aqueles pacientes que recebiam suporte contínuo (Meltrego et al., 1998, referido por Leff \& Warner, 2006). Um estudo de follow-up para avaliar a conversão de um programa de tratamento em hospital de dia para emprego apoiado verificou que $86 \%$ dos utentes estavam ainda a receber serviços dez anos mais tarde. (Salyers et al., 2004, referido por Leff \& Warner, 2006). Não surpreendente foi a verificação de que os consumidores empregados no follow-up atribuíam o seu sucesso ao apoio contínuo dos profissionais.

Em suma, é importante salientar que os serviços de acompanhamento são individualizados para se adequarem às necessidades únicas de cada indivíduo.

\section{O planeamento personalizado de beneficios}

Uma das grandes barreiras ao emprego é o medo de perder benefícios, daí a importância do fornecimento de aconselhamento nesta matéria como parte de um programa de emprego apoiado.

O técnico fornece ajuda ao consumidor para que ele compreenda as regras complexas que controlam os benefícios por incapacidade. $O$ aconselhamento de benefícios refere-se, portanto, ao planeamento contínuo para que os consumidores tomem decisões bem informadas em relação à Segurança Social, programas de ajuda médica e outros direitos governamentais. Um estudo de Vermont que dispunha de conselheiros de benefícios para trabalhar de perto com programas de emprego apoiado verificou que os rendimentos dos utentes duplicaram como resultado da intervenção (Bond, 2004, Leff \& Warner, 2006). 


\subsection{Reabilitação Residencial}

A habitação, além de ser um direito básico, é nalguns lugares o factor que mais limita o processo de desinstitucionalização e reforma psiquiátrica. O desenvolvimento da reabilitação psicossocial, a preocupação crescente com a defesa dos direitos humanos dos doentes mentais e a disseminação da possibilidade da sua recuperação e inclusão social têm levado a uma progressiva transferência destas pessoas para residências e outras estruturas comunitárias. Desta forma, os cuidados comunitários para a maioria das pessoas atingidas por doenças mentais de evolução prolongada concretizam-se através da disponibilização de instalações estruturadas de apoio (Comissão Nacional para a Reestruturação dos Serviços de Saúde Mental, 2007).

As doenças mentais levam à utilização de camas em hospitais psiquiátricos em duas circunstâncias: em primeiro lugar, na fase aguda; em segundo lugar, durante a convalescença ou num estado crónico irreversível que alguns pacientes apresentam. A experiência de muitos países na América, Ásia e Europa demonstrou, no primeiro caso, que uma cama localizada num hospital geral é o recurso mais adequado (WHO, 2001), garantindo um melhor apoio de outras especialidades e diminuindo o estigma associado às doenças psiquiátricas (Comissão Nacional para a Reestruturação dos Serviços de Saúde Mental, 2007). No segundo caso, as residências comunitárias têm com sucesso substituído as instituições de modelo asilar (WHO, 2001).

As residências colectivas, oferecendo diferentes graus de apoio, constituem o tipo mais comum de alojamento no Reino Unido e Estados Unidos. Grande parte do êxito deste tipo de residências pode ser atribuido à combinação de diversos factores: um ambiente semelhante ao domicílio familiar, apoio emocional dispensado pelos técnicos, desenvolvimento de competências sociais e supervisão no local. Muitas destas casas são edifícios reconvertidos, situados em zonas residenciais tranquilas, perto de lojas e de serviços de utilidade pública. Estes não se distinguem arquitectonicamente dos edifícios próximos e raramente ostentam qualquer sinal identificador (Trieman, 2000).

A privacidade, liberdade e responsabilidade são os valores preconizados na maioria das unidades residenciais para pessoas com doença mental. Estas estruturas comunitárias tentam conceder oportunidades para que os seus residentes readquiram a independência. A satisfação das necessidades básicas constitui o objectivo dos cuidados em muitos locais, juntamente com esforços para melhorar o desempenho social e a participação do utente na actividade de vizinhança, nomeadamente indo às compras e visitando amigos. Além disso, os residentes são encorajados a responsabilizarem-se por tomar os seus próprios medicamentos e por gerir o seu dinheiro (Trieman, 2000). 
A Richmond Fellowship, uma organização voluntária inglesa que oferece alojamento e oportunidades de trabalho, declarou a premissa de que cada unidade residencial deverá ficar ligada directamente a um local com oportunidades de trabalho (Leff \& Trieman, 2000).

Em suma, a reabilitação residencial tem sido, de forma significativa, identificada como uma estratégia fundamental para atingir a integração comunitária, ainda que seja necessária mais investigação nesta área (Bond et al., 2004).

\section{O estudo de caso: A Associação de Reabilitação Social e Desinstitucionalização de Doentes Psiquiátricos (ARSDOP)}

\section{Objectivos}

O principal objectivo deste estudo consiste em obter conhecimentos sobre a prática de reabilitação psicossocial, suas contingências e resultados por intermédio da descrição e análise intensiva da Associação de Reabilitação Social e Desinstitucionalização de Doentes Psiquiátricos (ARSDOP), um caso paradigmático e único, em diversos aspectos, na área da reabilitação psicossocial de doentes mentais severos. Pretendeu-se realizar uma descrição factual, literal, sistemática e completa dos programas de reabilitação psicossocial da Associação: formação profissional, emprego protegido, acompanhamento pós-colocação, na área da reabilitação profissional, e unidade de vida protegida, uma valência de reabilitação residencial.

\section{Metodologia}

Em termos metodológicos, a investigação realizada define-se como um estudo de caso, isto é, uma descrição e análise intensiva e holística de uma entidade, fenómeno ou unidade social, que se baseia essencialmente na compreensão dos fenómenos observados (Merriam, 1990, referido por Curado, 1995). O estudo de caso investiga um fenómeno contemporâneo dentro do seu contexto real, debruçando-se sobre uma situação específica que se supõe ser única em muitos aspectos e procurando descobrir o que há nela de mais essencial e característico. $O$ objectivo deste tipo de investigação não é, portanto, a generalização, mas produzir conhecimento acerca de objectos muito particulares.

Assim, esta investigação constitui um estudo de caso, em que a unidade de análise é uma Instituição Particular de Solidariedade Social, a Associação de Reabilitação Social e Desinstitucionalização de Doentes Psiquiátricos (ARSDOP), na qual se pretendeu conhecer o seu modelo de funcionamento global e, mais especificamente, 
os modelos de reabilitação profissional e residencial nela desenvolvidos. O nosso estudo de caso tem um cunho fortemente descritivo, isto é, não se pretendeu mudar a situação, mas dá-la a conhecer conforme ela existe, o que implica uma descrição factual, literal, sistemática e tanto quanto possível completa. O estudo de caso seguiu, de forma geral, uma abordagem pragmática, visando proporcionar uma perspectiva global e coerente do objecto de estudo e, com base no conhecimento analítico alcançado, formular questões para futuras investigações.

A investigação no terreno compreendeu duas fases essenciais. Procedeu-se, numa primeira etapa, a um contacto com a Instituição, no sentido de sensibilizar os técnicos e utentes para o estudo que se iria levar a cabo e de se tomar consciência do seu modelo geral de funcionamento. Nesta primeira fase, deu-se a conhecer a todos os intervenientes observados os objectivos do projecto de investigação. Nesta etapa, as observações não foram focalizadas e os principais objectivos foram o conhecimento dos participantes, o contacto com a rotina e a apreensão das regras formais e informais da Associação.

Numa segunda fase, após um período de afastamento para reflexão, foram utilizadas técnicas interactivas (métodos de observação participante e entrevista) e técnicas não interactivas (análise documental, por exemplo, relatórios, projectos, panfletos e dossiers da Associação).

Neste período, o enfoque do estudo foi orientado para conhecer e analisar os modelos de reabilitação profissional postos em prática na Associação, designadamente nas valências de formação profissional, emprego protegido e acompanhamento pós-colocação, não deixando de ser feita referência ao programa de reabilitação residencial (unidade de vida protegida).

\section{Evolução histórica e caracterização geral}

A ARSDOP, Associação de Reabilitação Social e Desinstitucionalização de Doentes Psiquiátricos, nasceu a 26 de Junho de 1990 por iniciativa de técnicos de saúde mental interessados na desinstitucionalização dos doentes mentais.

A ARSDOP é uma Instituição Particular de Solidariedade Social, sem fins lucrativos. Encontra-se sediada na Quinta de Arnes, freguesia de Alfarelos, concelho de Soure, em instalações do Estado Português, cedidas pelo Centro Psiquiátrico de Recuperação de Arnes - Ministério da Saúde.

A ideia de criar a ARSDOP surgiu a partir de um contexto muito próprio, quando em 1988 a Direcção de Serviços de Saúde Mental iniciou, a nível nacional, a implementação de um programa para a desinstitucionalização e reabilitação 
psicossocial de doentes mentais de evolução prolongada, remetendo para uma dimensão de dinâmica comunitária.

A inexistência de serviços de reabilitação psicossocial na zona centro do país despoletou o interesse das entidades tuteladas pelo Ministério do Trabalho e da Solidariedade, nomeadamente do Instituto de Emprego e Formação Profissional (I.E.F.P.). Neste contexto, em 1990, a antiga Colónia Agrícola de Arnes foi visitada, pela primeira vez, por responsáveis da Direcção de Serviços de Reabilitação do I.E.F.P., tendo surgido a ideia, após diagnóstico da situação, de ser criado um centro de emprego protegido.

Nesta altura, as formas de encarar e tratar as doenças mentais sofreram uma viragem significativa: pretendia-se passar dos cuidados hospitalares e da exclusão social para a integração na comunidade. É neste contexto que é criada, em 1990, a ARSDOP, que teve como sócios-fundadores responsáveis e técnicos de Saúde Mental do Centro Psiquiátrico de Recuperação de Arnes.

O percurso institucional da ARSDOP, desde 1990, tem-se pautado pelo desenvolvimento de projectos de reabilitação psicossocial, de forma a garantir uma diversidade de apoios complementares ao Sistema de Saúde Mental, constituindo a única Instituição Particular de Solidariedade Social, a nível da zona centro, vocacionada para a reabilitação do doente mental.

Quanto à estrutura organizacional da entidade, a Assembleia-geral é soberana nas decisões sobre os destinos da ARSDOP, atribuindo poderes de fiscalização ao Conselho Fiscal e mandatando a Direcção para a prossecução dos fins previstos nos seus estatutos. A coordenação técnica, composta por uma psicóloga e duas assistentes sociais, executa e faz executar as decisões da Direcção.

De forma a cumprir os seus objectivos, a ARSDOP desenvolve projectos no âmbito da reabilitação psicossocial, nomeadamente o centro de formação profissional, o centro de emprego protegido, o programa de acompanhamento pós-colocação e a unidade de vida protegida (unidade residencial), dignificando a qualidade de serviços prestados ao nível de cuidados continuados de saúde.

Os utentes da ARSDOP são encaminhados, maioritariamente, pelos Serviços de Saúde Mental da zona centro do país (Centro Psiquiátrico de Recuperação de Arnes, Centro Hospitalar Psiquiátrico de Coimbra, Hospital Santo André de Leiria) e, ainda, por serviços do Ministério da Justiça (Instituto de Reinserção Social), por serviços locais da Segurança Social, Câmaras Municipais e outros serviços comunitários (Centros Sociais e Paroquiais). Solicitam, também, directamente os serviços da ARSDOP, as pessoas portadoras de doença mental, familiares e amigos. 
Após o primeiro contacto desses serviços, a equipa da ARSDOP solicita o envio de relatórios (clínico e social). Posteriormente, é realizada uma entrevista de avaliação do candidato. Com os elementos que são fornecidos pelos relatórios, pela entrevista à própria pessoa e, se possível, a um familiar próximo, é verificado se os candidatos preenchem os critérios de admissão nos respectivos programas. As técnicas aconselham os utentes a iniciarem a sua reabilitação na ARSDOP integrando o centro de formação profissional.

A filosofia de intervenção da ARSDOP assenta numa visão da reabilitação direccionada para o recovery. A visão da reabilitação sobre o recovery é a de que, com apoio, as pessoas podem readquirir o funcionamento social, apesar de manterem sintomas, limitações, medicação e continuarem portadoras de doença mental.

\section{Análise dos programas de reabilitação}

\subsection{Formação Profissional}

A ARSDOP desenvolve, desde 1994, acções de formação profissional, tendo como objectivo último a participação activa do cidadão com doença do foro psiquiátrico, através da aquisição e desenvolvimento de competências para o desempenho de uma actividade profissional em meio competitivo de emprego.

\section{Objectivos}

Os objectivos do centro de formação profissional da ARSDOP são: facilitar o acesso à formação profissional de pessoas portadoras de doença mental, tendo em consideração as limitações específicas de cada uma; proporcionar uma formação inicial/qualificação e/ou reconversão profissional; recuperar capacidades perdidas e desenvolver novas capacidades; integrar o jovem/adulto no mercado normal de trabalho, garantindo uma igualdade de oportunidades; fomentar a divulgação das experiências formativas junto da comunidade, desmistificando o estigma da doença mental como garantia da igualdade de direitos e oportunidades fundamentais.

A reabilitação profissional, na valência de formação, visa proporcionar aos utentes a oportunidade e os meios para adquirirem os conhecimentos (saberes), as capacidades (saber-fazer) e as atitudes (saber ser) necessários para exercerem uma profissão.

\section{Destinatários}

Os destinatários do centro de formação profissional da ARSDOP são jovens adultos portadores de doença mental, de ambos os sexos, com idades compreendidas entre os 16 e os 45 anos, que pretendam obter uma qualificação profissional 
que lhes permita alcançar o mercado normal de trabalho. Os utentes deverão, ainda, ser seguidos nos serviços da especialidade, encontrando-se clinicamente estabilizados, ser autónomos nas actividades de vida diária e ter capacidades de desempenho mínimas.

\section{Cursos de formação e perfis profissionais}

Actualmente, o centro de formação profissional da ARSDOP dinamiza 7 cursos, com capacidade para 58 formandos, de ambos os sexos, estando o período de formação preparado para ter a duração de 1 a 4 anos.

Os cursos ministrados neste centro são: Construção Civil, Hortofloricultura, Limpeza, Cozinha e Restauração, Jardinagem, Informática e Artes Gráficas. Os currículos incluem formação tecnológica específica de cada área e formação complementar nas áreas de Alfabetização, Desenvolvimento Pessoal (treinos de autonomia e de competências sociais) e Educação Física. Não são exigidas habilitações mínimas para a frequência dos cursos, exceptuando os de Artes Gráficas e de Informática, para os quais é exigido o $9 .^{\circ}$ ano de escolaridade.

O curso de Construção Civil está direccionado para o saber de cariz prático, o que permite uma boa adaptação dos utentes, sendo uma área que gera interesse numa larga faixa etária, devido à elevada remuneração que hoje é praticada no mercado de trabalho. Os formandos que já terminaram o curso têm sido colocados em mercado normal de trabalho em pequenas empresas da região do Baixo-Mondego.

O curso de Hortofloricultura tem sido a escolha de muitos formandos. Em análise, pode dizer-se que isso é devido ao facto de uma grande percentagem de indivíduos que recorrem à ARSDOP serem provenientes da zona rural envolvente. A sua apetência para tarefas ligadas à natureza, mais especificamente, à hortofloricultura, e o facto de, na Quinta de Arnes, se poder proporcionar um agradável conjunto de tarefas formativas ao ar livre, provaram que este curso tem um elevado valor reabilitativo. $\mathrm{O}$ aumento da escolaridade da nossa população levou ao êxodo rural, gerando a necessidade e aumento da procura de trabalhadores agrícolas nos últimos anos. Existem algumas empresas no distrito, o que possibilita a integração dos formandos em mercado de trabalho.

O curso de Limpeza foi planificado para que a simplicidade e o carácter rotineiro das tarefas favoreçam o processo de aprendizagem. As empresas de prestação de serviços de limpeza têm proliferado, o que proporcionou à equipa da ARSDOP o estabelecimento de vários contactos com o objectivo de se realizarem estágios e posteriores colocações. Além disso, a ARSDOP constitui, ela própria, uma resposta para a integração destes formandos, visto que presta estes serviços à comunidade através do seu centro de emprego protegido. 
O curso de Cozinha e Restauração envolve tarefas muito diversificadas, gerando o interesse e uma boa adaptação por parte dos utentes. O facto da ARSDOP possuir instalações com equipamentos muito próximos da realidade deste sector de actividade é facilitador, tanto de aprendizagem e assimilação como da integração em mercado normal de trabalho.

O curso de Jardinagem permite a aquisição de boas competências técnicas, ao mesmo tempo que não exige um elevado grau de escolaridade, pelo que constitui uma resposta adequada à população-alvo. As políticas de sensibilização e requalificação ambiental que levam os municípios a investir na criação e manutenção de espaços verdes, por um lado, e o investimento na qualidade de vida por parte da população em geral, por outro, vieram promover a proliferação de empresas neste sector, provocando, assim, uma grande expansão do mercado de trabalho. É de referir que, nesta área, a ARSDOP conseguiu parcerias com empresas para a colocação em estágio e a própria Associação, através do centro de emprego protegido, constitui uma resposta de integração para estes formandos.

O curso de Informática é o alvo preferencial dos formandos com níveis mais elevados de escolaridade. O programa de formação atribui grande valor às tecnologias de informação e comunicação, na medida em que, actualmente, têm um carácter essencial no trabalho em empresas.

O curso de Artes Gráficas é uma aposta nas características das suas tarefas: se, por um lado, são tarefas rotineiras e repetitivas, facilitando a aprendizagem, por outro lado, dada a sua vertente prática e criativa, com uma multiplicidade de materiais e cores, permite uma boa adaptação dos formandos e motiva-os na execução das mesmas. Na nossa sociedade, o marketing e a publicidade têm assumido um lugar importante, pelo que os produtos e serviços só vendem e são crediveis se for realizada uma campanha eficaz e eficiente, criando condições para a expansão da prestação de serviços ligados às artes gráficas e à consequente procura de profissionais qualificados.

O centro de formação profissional da ARSDOP pretende formar profissionais com os seguintes perfis: servente de pedreiro; auxiliar de hortofloricultura ou trabaIhador agrícola; auxiliar de limpeza; auxiliar de cozinha; auxiliar de jardinagem ou jardineiro; auxiliar administrativo; auxiliar de impressor gráfico.

\section{Procedimentos/Metodologia}

A ARSDOP preconiza a elaboração de percursos de formação individualizados. Assim, além de ter em conta cada caso na sua individualidade (diagnóstico, situação clínica, nível de deterioração, detecção de capacidades intactas, ritmo 
de aprendizagem), permite, ainda, o ingresso de formandos em qualquer altura do ano, possibilitando a sua entrada, nos diversos cursos, no momento óptimo da sua motivação, o que beneficiará, indubitavelmente, a adesão e o sucesso do seu processo reabilitativo.

No entanto, apesar da especificidade de cada plano, podemos encontrar um conjunto de métodos de intervenção ao nível da reabilitação socioprofissional comuns a todos. Tendo em consideração que o objectivo da formação profissional é a integração do formando em mercado de trabalho, todos os cursos integram vários componentes de formação, nomeadamente, reabilitação funcional, valências teóricas nas vertentes sociocultural e científico-tecnológica, bem como, prática simulada e prática em contexto real de trabalho. A reabilitação funcional pretende desenvolver a autonomia pessoal (higiene pessoal, apresentação cuidada e utilização de transportes), a aprendizagem de atitudes profissionais correctas (conhecer hierarquias, conhecer regras), reforçar a auto-estima e a motivação. A componente teórica sociocultural caracteriza-se pelo desenvolvimento de competências de natureza pessoal, relacional, social e cultural, integrando áreas como alfabetização, técnicas de procura de emprego, higiene e segurança no trabalho e sensibilização ambiental. A componente teórica científico-tecnológica diz respeito à aquisição de competências específicas no domínio das tecnologias e actividades práticas. A prática simulada refere-se à experimentação em campos de treino (cozinha, oficina, estufa) dos processos e técnicas aprendidos na teoria, permitindo o manuseamento dos equipamentos e materiais sob a orientação do formador. A prática em contexto real de trabalho destina-se à consolidação das competências técnicas e à adaptação ao posto de trabalho (condições físicas, relacionais, sociais), constituindo uma efectiva aproximação ao mundo do trabalho e das empresas.

A metodologia base de cada curso abrange técnicas e métodos diversificados e adaptados ao perfil do público-alvo: métodos expositivos; demonstrativos, interrogativos e activos.

A equipa de recursos humanos afectos à formação profissional inclui uma psicóloga, uma técnica de colocação e acompanhamento em estágio, uma assistente social, formadores ( 6 formadores internos e 1 formador externo), dois auxiliares de formação e um coordenador técnico-pedagógico, sendo o último, o responsável máximo por todo o sistema.

A selecção dos formandos é feita tendo por base uma avaliação clínica e social enviada pelos parceiros com competência técnica. Após análise dos relatórios clínico e social, é realizada uma entrevista ao candidato pela equipa técnica com o objectivo de verificar se este reúne os requisitos necessários. A autonomia na vida activa, a motivação para frequentar a formação profissional e a estabilidade clínica são os critérios mais relevantes a ter em conta na decisão da sua integração. 
Os formandos têm como regalias uma bolsa de formação, subsídios de transporte, refeição e alojamento, quando residam a mais de $50 \mathrm{~km}$. Têm ainda um seguro de acidentes pessoais e um certificado de frequência.

O percurso formativo dos formandos é caracterizado por várias fases. Num primeiro momento, os formandos passam por um processo de avaliação, que contempla dados biográficos, experiência profissional e, de forma opcional, o início e desenvolvimento da doença. $\mathrm{Na}$ fase seguinte, os formandos passam uma semana em cada área de formação. O objectivo desta etapa é que os formandos percebam a dinâmica da instituição e avaliem qual o curso para o qual têm maior aptidão, de forma a fazerem a sua escolha em termos formativos. Após a realização do curso de formação, os formandos têm uma experiência de formação profissional em situação real de trabalho (estágio), com a duração máxima de 1 ano. O estágio é efectuado com apoio técnico em empresas das áreas profissionais, com as quais a ARSDOP tem protocolos. O estágio é um processo gradual de preparação vocacional e de experiência de trabalho, onde os participantes vão consolidar hábitos, competências e capacidades profissionais, até se considerarem prontos para, efectivamente, dentro de uma empresa, conseguirem efectuar as diversas tarefas e assim obterem um contrato de trabalho.

Dos formandos que completam o curso de formação profissional, só são integrados em regime de emprego protegido os candidatos que, a pós avaliação do percurso socioprofissional, não reúnam condições para integrar o meio competitivo de emprego, isto é, em que o prognóstico do seu processo de reabilitação implique acompanhamento estreito e uma intervenção multidisciplinar e intersectorial. Os formandos que apresentem um prognóstico de reabilitação favorável e que tenham concluído o curso e realizado um estágio com aproveitamento são integrados e acompanhados em mercado normal de trabalho, sempre que existam ofertas de emprego.

\section{Métodos de avaliação}

A avaliação formativa permite situar os formandos nos vários domínios do saber, em função do desempenho demonstrado; informar os formandos dos seus progressos; orientar, aconselhar e corrigir os formandos durante a formação. A técnica de observação é a mais utilizada, sendo mesmo insubstituivel, pelos formadores e equipa técnica, atendendo ao público-alvo a quem se destina a formação profissional, pessoas portadoras de doença mental severa, as quais necessitam de uma vigilância permanente dos comportamentos que vão tendo ao longo da sua reabilitação. São observados os comportamentos, reacções, aptidões, zelo, interesse, as dificuldades encontradas, os erros cometidos e outros. 
Para debater as informações obtidas, através da observação feita pelos vários intervenientes do processo formativo, são realizadas reuniões semanais ou quinzenais com formandos, formadores e equipa técnica. Para os formandos que se encontram em estágio, as reuniões são realizadas com o responsável da entidade receptora do estágio.

A avaliação sumativa permite verificar, no final da formação, se as competências adquiridas pelos formandos correspondem ao perfil desejado; avaliar os objectivos da formação; diagnosticar os pontos fracos e fortes da formação, através dos resultados obtidos, bem como recolher e processar dados com vista à melhoria do curso.

Na ARSDOP, a avaliação realizada é direccionada, avaliando o comportamento do formando, tomando por base o objectivo a ser atingido. É atribuída uma cotação aos formandos em relação ao trabalho realizado, tendo por fim estabelecer uma ordem de classificação consoante o grau, mais ou menos elevado, do domínio dos conhecimentos e competências que demonstram possuir. A escala de classificação utilizada tem a seguinte cotação: Muito Bom, Bom, Suficiente e Mau. Os instrumentos utilizados são: grelhas de avaliação (incluindo auto-avaliação dos formandos); lista de ocorrências quinzenal (comportamentos/atitudes dos formandos) e testes escritos e/ou orais para avaliar as competências/capacidades laborais.

A grelha de auto-avaliação visa estudar, comparar e reflectir sobre as possiveis discrepâncias e lacunas entre os dados avaliativos dos formadores e a opinião que os formandos têm do seu comportamento e desempenho nas tarefas da formação. Os formandos fazem, também, uma avaliação dos formadores (competências formativas e laborais) e da entidade formadora.

Os formadores preenchem uma grelha de avaliação mensal dos formandos, com o objectivo de analisar a relação entre tarefas ensinadas/tarefas aprendidas, identificando, desta forma, os seus ritmos de aprendizagem e autonomia, bem como os elementos que facilitam ou dificultam o processo de aprendizagem. Esta análise deverá incluir e tomar em linha de conta a relação formando-formador-meio.

Como se referiu acima, finda a etapa da formação teórica e simulada, os formandos que tiverem obtido aproveitamento realizam um estágio, considerando-se que o desempenho nos postos de trabalho constitui a prova fundamental às suas competências laborais e permitirá a sua colocação em mercado normal de trabalho. No estágio, é preenchida uma grelha de avaliação de forma a conhecer em que medida a aprendizagem anterior os colocou, de facto, aptos e capazes para assumirem responsabilidades e desempenharem com o nivel qualitativo esperado as suas funções e tarefas. 


\subsection{Emprego Protegido}

A ARSDOP preconiza que o exercício de uma actividade profissional remunerada é facilitador de integração e participação social, garantindo igualdade de direitos e oportunidades e conduzindo à melhoria da qualidade de vida dos seus utentes.

124 Neste sentido, foi estabelecido em 1990 um Contrato de Comodato entre a então Colónia Agrícola de Arnes (actual Centro Psiquiátrico de Recuperação de Arnes) e a ARSDOP, que permitiu a cedência pelo Estado Português de espaços agrícolas e sociais da Quinta de Arnes, possibilitando a criação de um centro de emprego protegido. Em Abril de 1992 foi celebrado, entre o I.E.F.P. (Instituto de Emprego e Formação Profissional) e a ARSDOP, um acordo de cooperação que permitiu a efectiva instalação e funcionamento do centro de emprego protegido de Arnes (CEP de Arnes).

\section{Objectivos}

A instalação e funcionamento do CEP/Arnes visa assegurar aos trabalhadores com doença mental de evolução prolongada, em regime de emprego protegido, o exercício de uma actividade remunerada, bem como a possibilidade de formação e/ou aperfeiçoamento profissional, que permita, sempre que possível, a integração em mercado competitivo de emprego.

\section{Destinatários}

O CEP de Arnes é destinado a doentes mentais de evolução prolongada, de ambos os sexos, com idade para o trabalho, que tenham concluído o adequado processo de reabilitação médica, manifestem suficiente autonomia nas actividades da vida diária e revelem capacidade suficiente de interpretação e execução das normas a que deverão obedecer as tarefas que Ihe forem cometidas. É ainda necessário para integrar o CEP que os utentes possuam capacidade média de trabalho não inferior a um terço da capacidade exigida a um trabalhador sem incapacidade no mesmo posto de trabalho.

Assim, os postos de trabalho criados em regime protegido destinam-se a beneficiar trabalhadores que atingem niveis de produtividade inferiores aos valores considerados normais, devido à sua condição física e psicológica.

\section{Actividades do CEP}

O CEP/Arnes funciona em moldes empresariais, possuindo autonomia económica, financeira e administrativa. Esta unidade abrange dois sectores de actividade económica: o sector primário, com uma unidade agro-pecuária, onde são desenvolvidas 
actividades de hortofloricultura e pecuária, e o sector terciário, que contempla uma unidade de prestação de serviços na área da limpeza e jardinagem.

O CEP tem capacidade para enquadrar 35 trabalhadores. No momento actual, a unidade agro-pecuária é constituída por um trabalhador na área da pecuária e dois trabalhadores na área de hortofloricultura. A unidade de prestação de serviços é constituída por três trabalhadores na área da jardinagem e sete trabalhadores na área da limpeza, sendo que a dimensão da última se justifica pelo aumento de serviços e pela necessidade de constituir duas equipas no dia-a-dia.

Até 1998, o Centro Psiquiátrico de Recuperação de Arnes constituía o único cliente do CEP em termos de aquisição de bens hortícolas e de serviços de limpeza e jardinagem. No entanto, a partir de 1998, a ARSDOP começou a prestar serviços na comunidade, facto que permitiu o crescimento do leque de clientes, assumindo algumas vertentes de primordial importância para o desenvolvimento do CEP: crescimento económico, maior capacidade competitiva no mercado, maior impacto e divulgação dos serviços prestados pela ARSDOP, melhoria qualitativa do processo de reabilitação profissional dos doentes e oportunidades de estágios em contexto real de trabalho. Desta forma, actualmente, a unidade de prestação de serviços do CEP orienta o seu campo de intervenção para o exterior e aposta na conquista de novos clientes (condomínios, empresas particulares, organismos públicos, entre outros).

\section{Procedimentos/Metodologia}

O CEP é composto por um bom número de recursos humanos, nomeadamente a equipa da unidade de produção, a equipa de enquadramento, a equipa de avaliação e acompanhamento, a equipa da comissão de fiscalização, serviços administrativos e Direcção.

A equipa da unidade de produção é composta pelos utentes, ou seja, trabalhadores em regime de emprego protegido (adiante designados trabalhadores REP), e trabalhadores de enquadramento. Compete aos trabalhadores de enquadramento orientar os trabalhadores REP, definindo critérios e seleccionando métodos pedagógicos de acordo com os objectivos; desenvolver sessões, transmitindo e desenvolvendo conhecimentos; proceder à avaliação de desempenho dos trabaIhadores REP, utilizando técnicas e instrumentos de avaliação, tais como inquéritos, questionários, trabalhos práticos e observação; demonstrar, através da execução, o gesto profissional, promovendo a sua repetição e correcção.

A equipa de enquadramento é composta por uma psicóloga, uma assistente social, um médico psiquiatra, um enfermeiro e técnicos de produção. Compete à psicóloga e à assistente social efectuar o levantamento das necessidades de apoio social, 
contribuir para a elaboração, por parte dos utentes, de projectos de vida e fazer o acompanhamento das famílias durante o processo de integração sócio-familiar. A psicóloga colabora, ainda, com os trabalhadores de enquadramento na resolução de problemas que surjam no decurso dos serviços e efectua o acompanhamento clínico dos trabalhadores REP, nomeadamente no que se refere a aspectos de relacionamento interpessoal e adaptação. O médico psiquiatra realiza observações e elabora o laudo psiquiátrico correspondente, que inclui diagnóstico, indicação terapêutica e conclusão sobre a responsabilidade laboral dos trabalhadores REP. Por sua vez, o técnico de produção estuda, concebe e orienta a execução de trabalhos relativos à produção na agro-pecuária e na prestação de serviços de limpeza e jardinagem.

A equipa de avaliação e acompanhamento, proveniente do Centro de Emprego da Figueira da Foz, é composta por um médico do trabalho, um técnico de reabilitação e um técnico de emprego. A equipa da comissão de fiscalização (composta por um economista do IEFP, que preside a esta comissão, e por um contabilista da ARSDOP) tem como principais funções verificar o cumprimento dos objectivos visados pelo CEP/Arnes e diligenciar quer no sentido da apresentação do plano de actividades e orçamento, quer a nível da apresentação do relatório de gestão e contas.

O Director do CEP, nomeado pela direcção da ARSDOP, é o responsável máximo por este projecto, com qualidades humanas e conhecimentos de gestão empresarial, de reabilitação e de perspectiva ergonómica da relação homem - posto de trabalho.

As pessoas que integram o CEP são encaminhadas pelo Centro de Emprego da Figueira da Foz, pelo Centro de Recursos Especializado para a área da Saúde Mental da zona geográfica ou são propostas pela ARSDOP através do centro de formação profissional.

Antes de se realizar um contrato de trabalho, os utentes do CEP passam por uma fase de estágio, que pode durar de um a nove meses, ainda que, por norma, se adopte o mínimo de três meses. No final do estágio, é realizada, pela equipa técnica da ARSDOP, trabalhadores de enquadramento e Centro de Emprego da Figueira Foz, a avaliação do défice de rentabilidade. Neste sentido, a equipa técnica e os trabalhadores de enquadramento preenchem um conjunto de grelhas de avaliação do desempenho do estagiário que permitem verificar se a sua rentabilidade é suficiente para a integração em emprego protegido. A grelha de avaliação do desempenho do estagiário inclui itens como volume e qualidade do trabalho realizado; conhecimento das tarefas; cooperação (atitude em relação à chefia e aos colegas); compreensão de normas e criatividade. Há, também, grelhas específicas para cada área, onde são avaliadas, em termos percentuais, as diferentes tarefas realizadas.

Os utentes só podem permanecer no CEP se a avaliação demonstrar, no mínimo, $33 \%$ de rentabilidade, pois como se referiu acima, é necessário, para integrar este 
projecto, possuir capacidade média de trabalho não inferior a um terço da capacidade exigida a um trabalhador sem incapacidade no mesmo posto de trabalho. $\mathrm{Na}$ ARSDOP, esta premissa é confirmada comparando a execução do utente com a do trabalhador de enquadramento, que é, neste caso, o trabalhador sem incapacidade.

O Centro de Emprego da Figueira da Foz financia anualmente os valores correspondentes ao défice de rentabilidade dos trabalhadores REP, tendo o CEP, através do sector de produção e comercialização, de assegurar a restante parte do salário, bem como os montantes globais referentes aos trabalhadores de enquadramento e os custos de funcionamento e gestão.

Por fim, é importante salientar que se o trabalhador do CEP demonstrar capacidade para integrar o mercado normal e houver essa possibilidade, o utente é transferido. O CEP é sempre a última alternativa.

\subsection{Acompanhamento pós-colocação}

A ARSDOP defende que a integração no mercado competitivo de trabalho é um processo delicado e com múltiplas barreiras, não resultando de um acto individual, mas de um conjunto que envolve vários parceiros, como as empresas, as famílias, a ARSDOP, como entidade de reabilitação e como serviço de colocação e, por último, a sociedade em geral.

No âmbito do programa POEFDS (Programa Operacional Emprego, Formação e Desenvolvimento Social), a ARSDOP desenvolve o projecto de acompanhamento pós-colocação, que se baseia no suporte continuado após a colocação no mercado normal de trabalho.

\section{Objectivos}

Este programa visa assegurar o direito ao trabalho, melhorando a sua manutenção, através de um sistema de apoio especializado, que ajuda o utente a ultrapassar as dificuldades de natureza social, psicológica e profissional.

\section{Destinatários}

Os destinatários do programa de acompanhamento pós-colocação são pessoas portadoras de doença mental, com idade entre os 16 e os 55 anos, provenientes do Centro de Formação da ARSDOP e dos Centros de Emprego do I.E.F.P., bem como entidades empregadoras que pretendam apoio por terem contratado trabalhadores com doença mental. 


\section{Actividades}

Os utentes em acompanhamento pós-colocação são distribuídos por diferentes actividades: agricultura, produção animal, caça, construção, comércio grosso e retalho, reparação de veículos, restauração e outras actividades de serviços colectivos sociais e pessoais.

Actualmente, encontram-se em acompanhamento pós-colocação dois utentes a desenvolver serviços na área da Limpeza (auxiliares de limpeza), dois na área administrativa e um na área da restauração (serviço de mesa). Estão ainda em acompanhamento pós-colocação um auxiliar de lar, uma costureira (trabalha por conta própria), um pedreiro, um servente de pedreiro, um segurança e uma lavadeira/engomadeira.

\section{Procedimentos/Metodologia}

Neste projecto, o apoio é garantido por um técnico de colocação e acompanhamento (assistente social), o qual é, também, responsável pela promoção de programas estratégicos de integração profissional com empresários da sub-região do Baixo Mondego.

O programa de acompanhamento pós-colocação comporta diversas fases e actividades. Num primeiro tempo, a equipa da ARSDOP desloca-se à empresa, de forma a verificar se há condições de higiene e segurança, obtendo dados para elaborar um relatório para o Instituto de Emprego. Posteriormente, agendam-se reuniões com a entidade empregadora (quando o utente é colocado numa pequena empresa, a equipa da ARSDOP reúne com o patrão; quando se trata de uma grande empresa, as reuniões são realizadas com o responsável da área).

Na primeira e segunda entrevistas, as técnicas apresentam a ARSDOP e seus objectivos, fazem protocolo com a empresa e debatem as condições de trabalho da pessoa a empregar. Além disso, e de forma mais específica, pode dizer-se que o objectivo primordial da primeira entrevista é ajudar a empresa na elaboração da candidatura ao prémio de integração de pessoas com deficiência ou incapacidade. Este prémio é atribuído às entidades empregadoras que celebram contratos de trabalho sem termo com pessoas deficientes/com incapacidade. O prémio de integração é concedido por uma só vez por cada trabalhador com incapacidade admitido e o seu valor é de doze vezes a remuneração mínima mensal garantida no seu valor mais elevado (ver decreto-lei $247 / 89$ de 5 de Agosto).

As reuniões seguintes com o responsável da entidade empregadora têm como principal finalidade explicar as dificuldades do utente, apelando para os seus pontos fortes e fracos. O diagnóstico é uma informação confidencial, sendo que nunca é fornecido à entidade empregadora, apenas se referindo que a pessoa 
sofre de doença mental. A equipa da ARSDOP refere, em reunião, que a situação está estável clinicamente e que acompanham os doentes às consultas da especialidade. É dada indicação ao responsável de possíveis sinais de descompensação do trabalhador, para que este possa chamar a equipa da ARSDOP num espaço de tempo válido que permita uma intervenção de sucesso.

Os utentes do programa de acompanhamento pós-colocação devem cumprir o mesmo que um trabalhador sem incapacidade. Porém, as técnicas sensibilizam o patrão para a necessidade de ter maior paciência e benevolência com o utente, devido às suas dificuldades, devendo, deste modo, ser-lhe proporcionada a possibilidade de realizar as tarefas para as quais tem mais capacidade.

A fase seguinte do processo caracteriza-se por reuniões entre a equipa da ARSDOP e o empresário, para que a primeira tome conhecimento do desempenho e evolução do utente na empresa e intervir, caso necessário.

Em relação ao acompanhamento específico do utente, num primeiro tempo, as técnicas explicam o funcionamento da empresa, as regras a cumprir e as possibilidades de transporte. A equipa técnica acompanha o primeiro dia de trabalho, permanecendo durante o processo inicial de integração na empresa.

Durante 3 anos o acompanhamento é regular: por vezes, a equipa técnica da ARSDOP dirige-se às empresas onde estão inseridos os utentes, nas restantes são estes que se deslocam à ARSDOP. Há ainda, de forma frequente, o contacto telefónico com a família. Neste período, as técnicas continuam a acompanhar os utentes aos Hospitais da Universidade de Coimbra e ao Hospital Sobral Cid, ainda que, com o passar do tempo, este acompanhamento se torne mais pontual, visto que se pretende, de forma paulatina, reforçar a autonomia. Durante este processo, as técnicas avaliam a satisfação e motivação, bem como o cumprimento da medicação e apoiam em questões causadoras de angústia e sofrimento, tanto a nivel laboral como pessoal.

É de salientar, que o projecto de acompanhamento pós-colocação foi promovido pelo I.E.F.P. e concebido para um ano, no entanto, como não foi criado outro programa que lhe desse continuidade, a equipa da ARSDOP a poia o trabalhador até sentir que é necessário, mesmo que implique suporte por vários anos (já foram acompanhados utentes neste programa durante mais de três anos).

A psicóloga da Associação salienta que, antes da existência deste projecto era muito frequente os utentes abandonarem os postos de trabalho passados $2 / 3$ meses após a sua inserção em mercado normal. Hoje, os participantes do projecto de acompanhamento pós-colocação permanecem anos nos mesmos postos trabaIho. A psicóloga refere ainda que os empresários estão cada vez mais receptivos a 
este tipo de iniciativas. Os insucessos em mercado normal devem-se, sobretudo, a descompensações clínicas.

Outro aspecto que importa ressaltar é o facto do projecto de acompanhamento pós-colocação estar intimamente ligado ao centro de formação profissional da ARSDOP, ou seja, todos os utentes que o integram deverão concluir um curso de formação, permitindo, desta forma, a possibilidade de realização de estágio antes de assinarem contrato. É importante salientar ainda que, no processo de colocação, a equipa tem sempre em conta as preferências e experiência profissional antes da doença.

\subsection{Unidade Residencial}

Em Março de 2001 foi celebrado um Acordo de Cooperação entre o Centro Regional de Segurança Social do Centro, a Administração Regional de Saúde do Centro, o Hospital Sobral Cid e a ARSDOP para a implementação de uma Unidade de Vida Protegida (UVP) na comunidade. Esta unidade insere-se no âmbito do Despacho Conjunto n. ${ }^{\circ}$ 407/98 do Ministério da Saúde e do Trabalho e Solidariedade.

A UVP é uma residência localizada em Alfarelos, com capacidade para 7 utentes de ambos os sexos.

\section{Objectivos}

A UVP é uma estrutura habitacional de transição entre o hospital e a comunidade, tendo em vista a promoção da autonomia individual e a reinserção social de pessoas adultas com problemática psiquiátrica grave e de evolução prolongada, mas com situação clínica estável.

Desta forma, os objectivos da UVP consubstanciam-se nos seguintes: possibilitar a integração social, desenvolver estratégias de maior investimento pessoal e sociofamiliar e diminuir os períodos de internamento.

\section{Destinatários}

Esta resposta social destina-se a jovens/adultos residentes no distrito de Coimbra, de ambos os sexos, com idades compreendidas entre os 16 e os 55 anos, cuja capacidade mental permita perspectivar uma reinserção socioprofissional, e que apresentem dificuldades ao nível de organização pessoal, inserção familiar e social, assim como em termos da manutenção autónoma de um espaço.

Por conseguinte, os critérios de elegibilidade são: processo clínico estabilizado e acompanhamento médico, apoio familiar aos fins-de-semana e capacidade para 
integrar programas de reabilitação (formação profissional, mercado normal de trabalho, emprego protegido, actividades ocupacionais).

\section{Actividades desenvolvidas}

As principais actividades desenvolvidas nesta estrutura residencial são: higiene pessoal, gestão do orçamento, medicação e consultas, confecção de refeições, utilização de serviços da comunidade, organização de tarefas individuais, saídas ao exterior e actividades lúdicas. Em suma, são trabalhadas competências residenciais e comunitárias.

\section{Procedimentos/Metodologia}

Os utentes são encaminhados para a UVP por Hospitais, Autarquias, Instituto de Reinserção Social e por pessoas da comunidade.

Após o encaminhamento é feita uma reunião de avaliação, onde estão presentes dois elementos da equipa da ARSDOP e dois elementos da equipa do Hospital Sobral Cid. Para que a pessoa encaminhada seja integrada na unidade residencial, os quatro elementos da equipa têm de estar de acordo relativamente ao facto de que a mesma irá beneficiar dos programas que a residência tem para oferecer. Esta mesma equipa reúne uma vez por mês para discutir os casos da UVP individualmente.

Os utentes comparticipam com 50\% dos seus rendimentos (bolsa de formação, emprego ou pensão social) a sua estadia na UVP.

O apoio técnico é realizado por uma assistente social, uma psicóloga e dois monitores de treinos de autonomia. A residência funciona das $17 \mathrm{~h}$ às $8 \mathrm{~h}$, sendo que durante este período está sempre presente um monitor; das $9 \mathrm{~h}$ às $17 \mathrm{~h}$, os utentes têm de ter, obrigatoriamente, uma ocupação. Os residentes da UVP estão integrados num dos programas de reabilitação profissional da ARSDOP (formação profissional, emprego protegido ou acompanhamento pós-colocação).

\section{Discussão}

O estado da arte mostra-nos que os cuidados de saúde mental não se podem basear exclusivamente no tratamento hospitalar, pelo que a diversificação de opções a nível de habitação, formação e emprego são medidas fundamentais no processo de recuperação. O nosso estudo revela que existe um esforço efectivo por parte da ARSDOP, desde a sua criação, no sentido de desenvolver estas diferentes respostas de reabilitação psicossocial. 
Durante muitos anos, a ideia de que os doentes mentais severos estariam condenados a não poder trabalhar foi aceite como uma verdade inquestionável, dando origem ao mito da incapacidade. Acreditava-se que estas pessoas apenas poderiam desempenhar actividades ocupacionais, consideradas por muitas delas monótonas e, por conseguinte, pouco motivadoras. A criação de programas de reabilitação profissional permitiu desmistificar falsas concepções acerca da capacidade de trabalho das pessoas com esquizofrenia. A ideia de que estas pessoas não são capazes de trabalhar, de assumir responsabilidades, gerir os seus bens, desenvolver as suas potencialidades e tomar decisões está muito difundida, mas já não se coaduna com os progressos de reabilitação verificados na ARSDOP.

A desinstitucionalização, tal como nos explica Bachrach (2000), pressupõe a necessidade de implementação de uma rede consistente de alternativas na comunidade. Fechar hospitais psiquiátricos sem alternativas na comunidade é algo tão (ou mais) perigoso como manter os doentes nos hospitais psiquiátricos, podendo, desta forma, correr-se o risco de criar um sistema perverso e contraproducente. $\mathrm{O}$ nosso estudo permitiu-nos verificar que a ARSDOP é uma estrutura constituída por respostas efectivas e profissionais com formação capazes de dar resposta à complexidade dos processos de integração social.

De acordo com Cuevas e Perona (1992, referido por Iraurgi et al., 1999), o principal objectivo da reabilitação psicossocial é ensinar às pessoas com doença psiquiátrica as competências e recursos de que precisam para viver satisfatoriamente dentro do seu ambiente social, premissa integralmente desenvolvida na ARSDOP, através do centro de formação profissional. De facto, o centro de formação profissional da ARSDOP não só desenvolve os conhecimentos técnicos essenciais para a integração em mercado de trabalho, mas também uma panóplia de outras competências pessoais e sociais essenciais no processo de reintegração e elaborando, inclusivamente, percursos de formação individualizados.

Quanto ao programa de emprego protegido, pode dizer-se que a crítica evidenciada na literatura, caracterizando este modelo segregador e institucional, é bem contornada pela ARSDOP, através da criação de uma unidade de prestação de serviços, que coloca os utentes em contacto com as pessoas do público.

Moreton (1992) sugere que as oficinas protegidas deveriam concentrar-se na formação e desenvolvimento de novas competências, facilitando a transição das pessoas com incapacidade de emprego protegido para mercado aberto. Corroborando a asserção de Moreton (1992), vimos que o funcionamento do CEP/Arnes visa assegurar aos trabalhadores com doença mental de evolução prolongada a possibilidade de formação e aperfeiçoamento, que permita, sempre que possível, a integração em mercado competitivo de emprego. 
O programa de acompanhamento pós-colocação é análogo ao modelo de emprego apoiado. A prática de emprego apoiado refere-se a programas com vista a ajudar pessoas com incapacidade a encontrar e manter emprego em mercado normal de trabalho. Da mesma forma, o programa de acompanhamento pós-colocação funciona como suporte continuado após a colocação no mercado competitivo.

Na revisão da literatura efectuada, verificámos que o emprego apoiado é conceptualizado como uma abordagem colocação-formação, contrariando a prática de formação pré-vocacional. Contrariamente, a ARSDOP adopta um paradigma formação-colocação, visto que o projecto de acompanhamento pós-colocação está estritamente ligado ao centro de formação profissional, ou seja, todos os utentes que o integram deverão concluir com aproveitamento um curso de formação.

Como vimos, o modelo de colocação e apoio individual não constitui um modelo isolado, mas um aperfeiçoamento do emprego apoiado. Em relação aos princípios desta abordagem sublinhados por Bond (1998; 2004), a ARSDOP só pratica alguns deles no projecto de acompanhamento pós-colocação.

O primeiro princípio, elegibilidade baseada na escolha do consumidor, não é cumprido na ARSDOP. Ao contrário do que preconiza o modelo de colocação e apoio individual, ou seja, a não exclusão de qualquer consumidor, a ARSDOP prevê critérios de elegibilidade, tais como completar um curso de formação profissional, situação clínica estável, autonomia nas actividades de vida diária e capacidades de desempenho mínimas.

A investigação revela que melhores resultados podem ser obtidos se os programas vocacionais forem parte integrada de uma equipa de saúde mental, constituindo o segundo princípio da abordagem de colocação e apoio individual enunciado por Bond (1998; 2004). O trabalho da ARSDOP é caracterizado por parcerias com instituições do sector da saúde, nomeadamente o Centro Psiquiátrico de Recuperação de Arnes e o Hospital Sobral Cid, desenvolvendo um trabalho integrado de acompanhamento médico e vocacional.

Bond $(1998 ; 2004)$ defende que os serviços devem estar focados em emprego competitivo ( $3 .^{\circ}$ princípio) e que os serviços protegidos são desnecessários. Concomitantemente, $04 .^{\circ}$ princípio enunciado por Bond (1998; 2004), procura rápida de emprego e colocação, sugere que a formação não aumenta a probabilidade de eventual emprego competitivo. Na ARSDOP, como vimos, estes princípios não se aplicam, pois o projecto de acompanhamento pós-colocação prevê, a montante, formação profissional, treino de competências pessoais e sociais e aconselhamento vocacional, variáveis consideradas preditores do sucesso em mercado competitivo. 
O $5{ }^{\circ}$ princípio do modelo de emprego apoiado (atenção às preferências da pessoa com doença mental) é posto em prática na ARSDOP, na medida em que a equipa de acompanhamento tem sempre em conta, no processo de avaliação e colocação, as preferências dos utentes e a experiência profissional antes da doença.

134 Outro princípio sublinhado por Bond é avaliação e apoio contínuos. O apoio é mantido por periodo indefinido, sendo que os programas de emprego apoiado permanecem ligados ao suporte dos utentes durante muito tempo após a colocação. O projecto de acompanhamento pós-colocação foi promovido pelo I.E.F.P.e concebido para um ano, no entanto, como não foi criado outro programa que the desse continuidade, a equipa da ARSDOP apoia o utente até sentir que é necessário. Como foi anteriormente mencionado, antes da existência deste projecto era muito frequente os utentes abandonarem os postos de trabalho passados poucos meses após a sua inserção em mercado normal. Actualmente, os participantes do programa de acompanhamento pós-colocação permanecem anos nos mesmos postos de trabalho, corroborando o estudo de Meltrego e colaboradores (1998, referido por Leff \& Warner, 2006) de avaliação de pacientes três anos e meio a pós a sua integração em mercado normal, em que verificaram que o trabalho era mais provável para os pacientes que tinham recebido suporte contínuo.

O último princípio enunciado por Bond (1998; 2004) é o planeamento personalizado de beneficios. A ARSDOP desenvolve este trabalho no seu projecto de acompanhamento pós-colocação, que inclui, por exemplo, suporte na resolução de problemas que possam surgir na Segurança Social.

Uma importante questão suscitada na literatura é que os resultados em emprego competitivo parecem ser melhores do que em emprego protegido. De facto, a presente investigação não nos permite responder a esta questão. Porém, pela observação realizada, é notório que existem pessoas que, devido à incapacidade causada pelos seus sintomas, não possuem as competências necessárias para aceder ao mercado normal de trabalho. Esta constatação remete-nos para a seguinte questão: será que as diferenças nos resultados são devidas ao programa ou à pessoa? As pessoas que estão em emprego protegido estão mais incapacitadas pelos seus sintomas psiquiátricos, daí que resultados não vocacionais, como auto-estima e qualidade de vida, possam não ser tão elevados. Pelo exposto, este trabalho suscita-nos o interesse de investigar de que forma estes programas divergem entre si em termos de resultados não vocacionais, sendo necessário, para tal, controlar a variável nível de psicopatologia, para que não cheguemos a conclusões enviesadas acerca da sua diferente efectividade.

Por fim, o processo de reabilitação só é completo e efectivo quando as pessoas com doença mental têm oportunidade de viver dentro do seu meio social, daí se 
ter assistido, nos últimos anos, à sua progressiva transferência para residências comunitárias. Complementando o seu trabalho de reabilitação profissional, a ARSDOP cria, em 2001, uma estrutura habitacional de transição entre o hospital e a comunidade. As pessoas com doença mental severa que apresentam dificuldades ao nivel da organização pessoal, inserção familiar e social, assim como em termos de manutenção autónoma de um espaço, têm, nesta residência, a preparação necessária para fazerem uma reintegração comunitária de sucesso.

A literatura defende que cada unidade residencial deve estar ligada a um local com oportunidades de trabalho. Na ARSDOP, os utentes que residem na UVP integram um dos programas de reabilitação profissional da Instituição (formação profissional, emprego protegido ou acompanhamento pós-colocação), criando condições para uma efectiva desinstitucionalização.

A promoção da autonomia e a construção de novos significados para a vida deverão ser objectivos substanciais nestas residências, caso contrário, corremos o risco de institucionalizar os pacientes na comunidade, pois o modelo asilar não se consubstancia em instituições vastas ou isoladas. Os asilos também podem existir na comunidade.

Em suma, esta investigação remete-nos para a necessidade de maior conhecimento acerca da contribuição do trabalho para a recuperação de pessoas com doença mental severa. A oportunidade de trabalho pode ser uma resposta adequada e com benefícios terapêuticos, no entanto, é um entre muitos complexos factores que afectam a pessoa e, como tal, deve ser visto como parte do espectro de cuidados. O trabalho facilita a participação do indivíduo na sociedade, promovendo a sua inclusão. Benefícios indirectos podem incluir uma redução do estigma, melhoria das relações familiares ou um estímulo ao bem-estar subjectivo, não obstante, todas estas hipóteses precisam de ser testadas.

A informação recolhida neste estudo de caso sugere, assim, algumas questões específicas a avaliar em investigação futura. Será o trabalho clinicamente benéfico para as pessoas com doença mental de evolução prolongada? Qual o impacto do trabalho no funcionamento, auto-estima e qualidade de vida dos doentes com esquizofrenia? Quais são os custos e os benefícios para a sociedade do trabalho de pessoas com problemas de saúde mental?

\section{Conclusões}

A reabilitação psicossocial no domínio da saúde mental é uma componente preponderante na recuperação de doentes mentais severos, devendo, por isso, ser 
integrada no processo de intervenção, desde o seu início, conforme recomenda 0 $1 .^{\circ}$ ponto das Conclusões do I Congresso de Reabilitação e Inclusão na Saúde Mental - O Papel das Famílias e das Redes de Apoio Social (Abreu e Santos, 2008).

Como refere Leff (2008), os serviços de saúde mental deverão ter como objectivo a 136 multiplicidade, prestando tanto quanto possivel os modelos neste trabalho analisados, pois as pessoas com doença mental não constituem um grupo homogéneo, mas representam uma ampla variedade de capacidades e graus de tolerância à pressão que um trabalho envolve.

Esta investigação mostrou-nos que os cuidados comunitários são, de facto, mais humanos, confirmando que muitas pessoas com doença mental podem ter hoje uma vida mais feliz e esperançosa do que jamais teriam em sistemas de cuidados de orientação asilar.

Em suma, pode dizer-se que este trabalho não "fecha tarefas". Pelo contrário, abre novas perspectivas de investigação-acção, pois só assim poderão criar-se equipamentos e serviços com notável efectividade. É pelas pessoas com doença mental que iremos continuar a trabalhar, para que tenham uma vida digna e com significado, pois como refere Benjamin Mayes (citado por Laborinho Lúcio, 2008) "temos de perceber que a tragédia na vida não reside em não alcançar o objectivo, a tragédia na vida é não ter um objectivo para alcançar; não é uma calamidade morrer sem se cumprirem os sonhos, mas é uma calamidade não poder sonhar; não é uma desgraça não alcançar as estrelas, mas é uma desgraça não ter estrelas para alcançar".

\section{Bibliografia}

Abreu, M.V. e Santos, E.R. (2008). O Papel das Familias e das Redes de Apoio Social - Actas do Primeiro Congresso de Reabilitação e Inclusão na Saúde Mental. Coimbra: Edições Almedina.

Almeida, J. C. (2008). Prefácio. In J. Leff e R. Warner, Inclusão Social de Pessoas com Doença Mental. Coimbra: Edições Almedina.

American Psychiatric Association (2000). Manual de Diagnóstico e Estatística das Perturbações

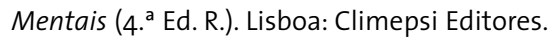

Anthony, W. A. (1993). Recovery from mental illness: the guiding vision of the mental health service system in the 1990s. Psychiatric Rehabilitation Journal, 16, 11-23.

Bachrach, L. (2000). Ensinamentos da experiência Americana na prestação de serviços de base comunitária. In J. Leff (Ed.), Cuidados na comunidade: Ilusão ou realidade (pp. 47-64). Lisboa: Climepsi Editores.

Becker, D. R., Bebout R. R., \& Drake, R. E. (1998). Job preferences of people with severe mental illness: A replication. Psychiatric Rehabilitation Journal, 22, 46-50. 
Becker, D. R., Drake, R. E., \& Naughton, W. J. (2005). Supported employment for people with co-occuring disorders. Psychiatric Rehabilitation Journal, 28, 332-338.

Becker, D., Whitley, R., Bailey, E. L., \& Drake, R. E. (2007). Long-term employment trajectories among participants with severe mental illness. Psychiatric Services, 58, 922-928.

Becker, D. R., Xie, H., McHugo, G. J., Halliday, J., \& Martinez, R. A. (2006). What predicts supported employment program outcomes?. Community Mental Health Journal, 42, 303-313.

Beddel, J. R., Draving, D., Parrish, A., Gervey, R., \& Guastadisegni, P (1998). A description and comparison of experiences of people with mental disorders in supported employment and paid prevocational training. Psychiatric Rehabilitation Journal, 21, 279-283.

Bellack, A. S. (2004). Skills Training for people with severe mental illness. Psychiatric Rehabilitation Journal, 27, 375-391.

Bond, G. R. (1998). Principles of the Individual Placement and Support model: Empirical support. Psychiatric Rehabilitation Journal, 22, 11-23.

Bond, G. R. (2004). Supported employment: evidence for an evidence-based practice. Psychiatric Rehabilitation Journal, 27, 345-359.

Bond, G. R., Salyers, M. P., Rollins, A. L., Rapp, C. A., \& Zipple, A. M. (2004). How evidence-based practices contribute to community integration. Community Mental Health Journal, 40, 569-588.

Bogdan, R. \& Biklen, S. K. (1982). Qualitative research for education: An introduction to theory and methods. Boston: Allyn and Bacon.

Buckley, P., Bahmiller, D., Kenna, C. A., Shevitz, S., Powell, I., \& Fricks, L. (2007). Resident Education and Perceptions of Recovery in Serious Mental illness: observations and commentary. Academic Psychiatry, 31, 435-438.

Busschbach, J., \& Wiersma, D. (2002). International Report: Does Rehabilitation meet the needs of care and improve the quality of life of patients with schizophrenia or other chronic mental disorders?. Community Mental Health Journal, 38, 61-70.

Cardoso, C. M. (2008). Nódoas na alma: a medicina e a loucura. Porto: Gradiva.

Carrier, J., \& Kendall, I. (2000). Evolução da Política. In J. Leff (Ed.), Cuidados na comunidade: Ilusão ou realidade? (pp. 23-45). Lisboa: Climepsi Editores.

Comissão Nacional para a Reestruturação dos Serviços de Saúde Mental. (2007). Reestruração e Desenvolvimento dos Serviços de Saúde Mental em Portugal: Plano de Acção 2007-2016. Consultado em Abril 2008: http://www.portugal.gov.pt/NR/rdonlyres/ D55589oE-A1A7-4703-BF98-4D1EDFB35DB1/o/Rel_Reestruturacao_Saude_Mental1.pdf.

Cook, J. A. (2006). Employment barriers for persons with psychiatric disabilities: update of a report for the President's Commission. Psychiatric Services, 57, 1391-1405.

Cordo, M. (2008). Reabilitação e cuidados continuados: um modelo por antecipação. In M. V. Abreu e E. R. Santos. O Papel das Familias e das Redes de Apoio Social - Actas do Primeiro Congresso de Reabilitação e Inclusão na Saúde Mental. Coimbra: Edições Almedina.

Crowe, T. P., Deane, F. P., Oades, L. G., Caputi, P., \& Morland, K. G. (2006). Effectiveness of a collaborative recovery training program in Australia in promoting positive views about recovery. Psychiatric Services, 57, 1497-1500.

Curado, A. P. (1995). A construção do projecto educativo de escola: estudo de caso numa escola secundária. Lisboa: Instituto de Inovação Educacional, Ministério da Educação.

Decreto Lei ${ }^{\circ}{ }^{\circ} 40 / 83$ de 25 de Janeiro. Diário da República n. ${ }^{\circ}$ 20/83 - I Série A. Ministério do Trabalho. Lisboa. 
Decreto Lei n. ${ }^{\circ} 247 / 89$ de 5 de Agosto. Diário da República n. ${ }^{\circ}$ 179/89 - I Série. Ministério do Emprego e Segurança Social. Lisboa.

Despacho Conjunto n. ${ }^{\circ}$ 407/98 de 18 de Junho. Diário da República n. ${ }^{\circ} 138 / 98$ - Il Série. Ministério da Saúde e Ministério do Trabalho e Segurança Social. Lisboa.

Decreto-lei 35/99 de 5 de Fevereiro. Diário da República n. ${ }^{\circ} 30 / 99$ - I Série A. Ministério da Saúde. Lisboa.

Drake, R. E., Becker, D. R., Bond, G. R., \& Mueser, K. T. (2003). A process analysis of integrated and non-integrated approaches to supported employment. Journal of Vocational Rehabilitation, 18, 51-58.

Erickson, F. (1986). Qualitative methods in research on teaching. In M. C. Wittrock (Ed.), Handbook of research on teaching (pp.119-161). New York, NY: Mcmillan.

Gameiro, A. (2008). Reabilitação psicossocial e inclusão na pós-psiquiatria: O estigma de um rótulo discriminatório, seus efeitos anti-empoderamento e sua redução. In M. V. Abreu e E. R. Santos. O Papel das Famílias e das Redes de Apoio Social - Actas do Primeiro Congresso de Reabilitação e Inclusão na Saúde Mental. Coimbra: Edições Almedina.

Goldberg, D. (1991). Cost effectiveness in the treatment of schizophrenia. Schizophrenia Bulletin, 17, 453-460.

Hallam, A. \& Schneider, J. (1999). Sheltered work schemes for people with severe mental health problems. Journal of Mental Health, 8, 171-186.

Hutchinson, D. S., Anthony, W. A., Ashcraft, L., Johnson, E., Dunn, E. C., Lyass, A., \& Rogers, E. S. (2006). The personal and vocational impact of training and employing people with psychiatric disabilities as providers. Psychiatric Rehabilitation Journal, 29, 205-213.

Iraurgi, I., Bombin, I., \& Imaz, I. (1999). Professional training in the rehabilitation of people with psychiatric disability. Psychiatric Rehabilitation Journal, 23, 175-180.

Leff, J. (1996). Quality of life of long-stay patients discharged from two psychiatric institutions. Psychiatric Services, 47, 62-67.

Leff, J. (2000). Cuidados na comunidade: Ilusão ou realidade? (J. N. Almeida, Trad.). Lisboa: Climepsi Editores (Obra original de 1997).

Leff, J. (2008). Inclusão social de pessoas com doença mental: a importância do trabalho. In M. V. Abreu e E. R. Santos. O Papel das Familias e das Redes de Apoio Social - Actas do Primeiro Congresso de Reabilitação e Inclusão na Saúde Mental. Coimbra: Edições Almedina.

Leff, J., \& Trieman, N. (2000). A criação de um service psiquiátrico completo na comunidade. In J. Leff (Ed.), Cuidados na comunidade: Ilusão ou realidade? (pp. 233-247). Lisboa: Climepsi Editores.

Leff, J. \& Warner, R. (2006). Social Inclusion of People with Mental Illness. New York: Cambridge University Press.

Lúcio, L. (2008). Inclusão e Solidariedade: Justiça e Desenvolvimento Social. In M. V. Abreu e E. R. Santos. O Papel das Famílias e das Redes de Apoio Social - Actas do Primeiro Congresso de Reabilitação e Inclusão na Saúde Mental. Coimbra: Edições Almedina.

Masson, J-M. ( 1999). Soins et Assistance Prodigués aux Alienés par les Frères de Saint Jean de Dieu dans la France du XVIIle Siécle. Pour une contibution à la réflexion sur la place de l'humanisme dans la pratique psychiatrique. Thèse de Doctorat em Médicine, Université de Bordeaux 2

Moreton, T. (1992). Sheltered Employment: Gateway or "Road Block"?. University Press, 21, 37-54. 
Ornelas, J. H. (2008). Psicologia comunitária: contributos para o desenvolvimento de serviços de base comunitária para pessoas com doença mental. In M. V. Abreu e E. R. Santos. O Papel das Famílias e das Redes de Apoio Social - Actas do Primeiro Congresso de Reabilitação e Inclusão na Saúde Mental. Coimbra: Edições Almedina.

Serra, A. V. (1999). O stress na vida de todos os dias. Coimbra: Edição do Autor.

Shorter, E. (1997). A History of Psychiatry: From the Era of the Asylum to the Age of Prozac. New York: John Wiley \& Sons, Inc.

Portaria 348 - A/98 de 18 de Junho. Diário da República n. ${ }^{\circ}$ 138/99 - I Série B. Ministério do Trabalho e da Solidariedade. Lisboa.

Trieman, N. (2000). Perspectivas sobre os cuidados na comunidade: pacientes, técnicos e público. In J. Leff (Ed.), Cuidados na comunidade: ilusão ou realidade? (pp. 77-95). Lisboa: Climepsi Editores.

World Health Organization. (2001). Mental health: new understanding, new hope. Geneva: World Health Organization.

Wolff, G. (2000). Atitudes dos meios de comunicação e do público. In J. Leff (Ed.), Cuidados na comunidade: ilusão ou realidade? (pp. 183-203). Lisboa: Climepsi Editores.

Yin, R. (1984). Case study research: Design and methods. Newbury Park, CA: Sage.

\section{Psychosocial Rehabilitation of People with Schizophrenia: A Case Study}

Recent changes in the psychiatric paradigm related to the deinstitutionalization process presuppose the development of services of community integration. Studies conducted in other countries show better results in psychosocial rehabilitation programs than treatment in psychiatric hospitals. However, in Portugal mental health services are not consistent with the state of the art in the area. In this sense, the main goal of this work is to know and to analyse an experience, which is unique for its characteristics, of psychosocial rehabilitation in the area of mental illness, in our region.

This research is a case study and the unity of analysis is a Private Institution of Social Solidarity, the Association of Social Rehabilitation and Deinstitutionalization of Psychiatric Patients (ARSDOP), in which we have sought to describe its global functioning model and, more specifically, its work and residential rehabilitation models.

KEYWORDS: Rehabilitation; Schizophrenia; Work. 